\title{
Uma Trajetória Transdisciplinar: nota biobibliográfica
}

Evandro Oliveira de Brito*

Universidade Estadual do Centro-Oeste (UNICENTRO), Paraná, Brasil

E-mail: evandrobritobr@yahoo.com.br

\section{Ilka Boaventura Leite ${ }^{* \star}$}

Universidade Federal de Santa Catarina, Florianópolis, Brasil E-mail: ilka.leite@ufsc.br

\section{Luiza Brandes de Azevedo Ferreira ${ }^{* * *}$}

Universidade Federal de Santa Catarina, Florianópolis, Brasil E-mail: luizabaf@gmail.com 


\section{Resumo}

Esta nota biobibliográfica pretende ser uma síntese da trajetória de Guerreiro Ramos, suas obras, pretende ainda trazer um pouco dos desdobramentos ocorridos a partir da influência desse importante pensador brasileiro na produção acadêmica atual. Para tanto, optou-se por abordar esta nota a partir de três eixos. No primeiro, são abordados os aspectos biográficos, trazendo de forma resumida acontecimentos significativos de sua história de vida a partir de uma linha temporal cronológica. Em seguida, faz-se um apanhado sobre a produção acadêmica de artigos, dissertações e teses, dos últimos anos, que fazem referência a Guerreiro Ramos, de maneira a trazer elementos para se pensar os desdobramentos de suas obras na atualidade. Por último, apresenta-se um levantamento dos principais livros escritos pelo autor, sobretudo tomando como parâmetro a primeira edição de cada obra.

Palavras-chave: Guerreiro Ramos. Biografia.

\section{Abstract}

This bio-bibliographical note is intended to be a summary of the path of Guerreiro Ramos, his works, and bring some of the developments that took place from the influence of this important Brazilian thinker in the current academic production. Therefore, we have chosen to address this note from three axes. In the first, we will cover biographical aspects, briefly bringing significant events of his life story from a chronological timeline. Then we will make an overview of the academic research articles, dissertations and theses, in recent years, which refer to Guerreiro Ramos, in order to bring elements to think about the ramifications of his works today. Finally we bring a survey of major books written by the author, especially taking as parameter the first edition of each work.

Keywords: Guerreiro Ramos. Biography. 


\section{Introdução}

uerreiro Ramos foi um importante intelectual brasileiro que teve

Juma vida pública muito rica e diversificada, embora seja ainda pouco conhecido no Brasil. Essa é a razão pela qual esta nota biobibliográfica poderá auxiliar estudantes, curiosos e estudiosos a encontrar importantes subsídios para impulsionar um maior conhecimento sobre a sua vida e obra, que sem dúvida é inesgotável. É impressionante a variedade de campos e áreas de atuação em que encontramos sua participação. Podemos apontar dentre eles a atuação acadêmica (como professor, escritor e conferencista); política (como assessor de Getúlio Vargas e Deputado Federal pelo Rio de Janeiro); jornalística (colaborou com "O Imparcial", da Bahia, "O Jornal", do Rio de Janeiro); militante do movimento negro (como integrante do Teatro Experimental do Negro (TEN), do Instituto Nacional do Negro e do Jornal do Quilombo) e do movimento integralista e católico na Bahia. Além disso, escreveu poesias ainda na juventude que foram reunidas no livro "O Drama de ser dois", publicado em 1937.

Esta nota pretende ser uma síntese da trajetória de Guerreiro Ramos, suas obras, bem como trazer um pouco dos desdobramentos ocorridos a partir da influência desse importante pensador brasileiro na produção acadêmica atual. Para tanto, optamos por abordar esta nota a partir de três eixos. No primeiro, abordaremos aspectos biográficos, trazendo de forma resumida acontecimentos significativos de sua história de vida a partir de uma linha temporal cronológica. Em seguida, faremos um apanhado sobre a produção acadêmica de artigos, dissertações e teses, dos últimos anos, que fazem referência à Guerreiro Ramos, de maneira a trazer elementos para se pensar os 
desdobramentos de suas obras na atualidade. Por último traremos um levantamento dos principais livros escritos pelo autor, sobretudo tomando como parâmetro a primeira edição de cada obra.

\section{Nota Biográfica}

Alberto Guerreiro Ramos nasceu em 13 de setembro de 1915 em Santo Amaro da Purificação, Bahia e era filho de Vítor Juvenal Ramos e de Romana Guerreiro Ramos. Há uma hipótese de que seu pai, nascido livre ainda no regime escravocrata brasileiro, tenha sido filho de escravizados e sua mãe, angolana, havia sido vendida pela própria família aos traficantes de escravos ${ }^{1}$. Sabe-se também que ele casou-se com Clélia Guerreiro Ramos, com quem teve dois filhos (Siqueira, 2008).

Em função da origem humilde ressaltada pelo próprio filho, Ramos entrou no mercado de trabalho aos 11 anos, exercendo a função de lavador de frascos em uma farmácia de Salvador (Oliveira, 1995, p. 145). A ambição de estudar surgiria logo em seguida, quando o destino colocaria em suas mãos e livro "alegria de Viver" de Marden. Estimulado por sua mãe, Ramos frequentou o curso secundário na capital do estado no Ginásio da Bahia, instituição frequentada pelas elites baianas (Nascimento, 2003).

A vocação de Ramos para a atividade intelectual, que logo o colocaria na vida acadêmica, é destacada pelo acesso que ele possuía à produção filosófica europeia dos anos 30 (Oliveira, 1995, p. 137).

No entanto, a possibilidade de aquisição destas obras, revistas literárias e filosóficas resultava das suas primeiras atividades docentes. A partir dos 14 anos de idade, Ramos se tornara professor particular de matemática de seus colegas ricos e destinava sua renda principalmente à aquisição de obras existencialistas.

Aos 17 anos de idade, ano em que ingressou como jornalista no "O Imparcial", Ramos passou a dividir suas atividades de leituras com a experiência desestimulante da militância junto ao integralismo, em companhia de Rômulo Almeida. O pouco valor que ele atribuía às atividades de militância, frente ao 
grande valor com que destaca suas atividades de leituras dos clássicos, o levou a esgotar toda a produção literária disponível sobre o tema, antes de abandoná-lo (Oliveira, 1995, p. 137-138).

Com 19 anos de idade, fez uma conferência sobre Rui Barbosa no Ginásio da Bahia e precisou ser acompanhado por um professor para não ser linchado, "[...] pois os conceitos que emitira sobre o grande homem não agradara os ouvintes" (Nascimento, 2003, p. 2). A sua perspectiva de análise acerca de Rui Barbosa não foi restrita apenas à oratória, pois anos depois publicou um ensaio crítico sobre Rui Barbosa "[...] que lhe valeu ódios, represálias, e ataques em quase todos os jornais de Salvador" (Nascimento, 2003, p. 2).

$\mathrm{O}$ valor que Ramos atribui às suas atividades intelectuais tem uma função interessante nos seus argumentos, pois ele toma esta vocação como base para justificar a sua primeira participação na gestão pública, como secretário assistente de educação.

A.A. - Qual era a sua função na administração Landulfo Alves?

G.R. - Quando Landulfo Alves se tomou interventor na Bahia, um homem chamado Rômulo Almeida foi incumbido de atrair as inteligências moças de Salvador. Varias pessoas foram recrutadas, e entre elas eu. Eu era muito jovem - completava 18 anos - quando fui nomeado assistente na Secretaria de Educação, que era chefiada pela Isaias Alves. (Oliveira, 1995, p. 134)

As atividades de Ramos que despertaram o interesse de Rômulo Almeida consistiam fundamentalmente naquelas atividades decorrentes de sua vida como escritor adolescente, influenciado pela filosofia francesa de orientação existencial cristã. Nessa etapa de sua vida, o vínculo com o catolicismo não era apenas teórico, pois Ramos fundou o centro de cultura Católica e criou uma revista, além de fazer várias palestras. Se relevarmos o fato, como veremos adiante, de que Ramos se considera um intelectual autodidata, torna-se muito interessante a declaração acerca da influência intelectual que o padre Béda Keckeisen exerceu sobre sua formação. Assim, diz ele:

Minha formação foi católica. Fui educado, de uma certa maneira, por um padre alemão dominicano, dom 
Beda Keckeisen, que foi o autor do primeiro missal em português. Era em latim, e ele fez em português. Dom Béda Keckeisen foi, durante muitos anos, quase um mentor. Eu nunca tive mentor, mas ele foi um homem por quem eu tinha uma grande simpatia. Freqüentei aulas de tomismo no mosteiro de São Bento, estudei profundamente o tomismo, quando tinha uns 19, 20 anos, através do Curso de filosofia do Maritain; li varias vezes aquele compendio. Conhecia quase toda a obra dele, ou o máximo que se podia conhecer. E a literatura francesa: Daniel Rops, o novelista sobre quem Afranio Colltinho escreveu um livro, François Mauriac, historiadores da literatura francesa, como Albert Daudet. (Oliveira, 1995, p. 137-138)

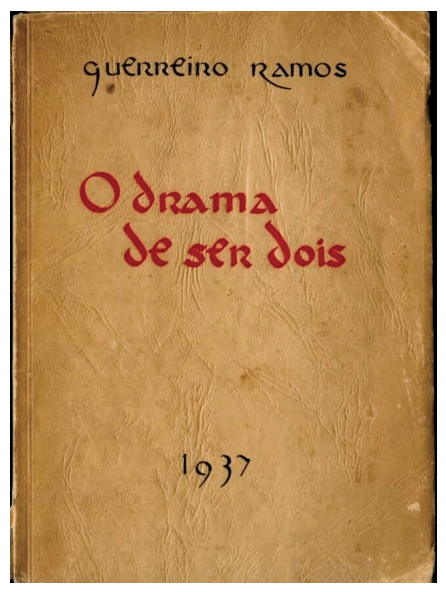

Ramos sugere, por meio da descrição dos detalhes de seu encontro com Jacques Maritain², que não se tratava de uma influência passiva. A recepção passiva das teorias europeias seria, alguns anos mais tarde, o critério para a rejeição das propostas metodológicas apresentadas pelos cientistas sociais brasileiros. Contrário à recepção passiva das teorias europeias, o Guerreiro deixa transparecer que a forte ligação pessoal existente entre filósofos franceses e o grupo de jovens intelectuais ao qual ele pertencia era demarcada por uma atitude reflexiva capaz de contribuir para o aprimoramento da filosofia existencial ${ }^{3}$.

Ao contrário de algumas análises, que consideram esta fase da vida de Ramos como um momento de imaturidade, é fundamental relevarmos que este foi o contexto da elaboração da obra “O Drama de ser dois" (1937). Se por um lado, como ressalta o próprio Guerreiro, esta obra não merece consideração pelo fato de não possuir relevância acadêmica, científica ou literária, por outro lado, ela deve ser tomada como norte por todos que pretenderem compreender o sentido mais geral da produção acadêmica, científica e literária de Ramos.

Esta obra consiste no "lugar" a partir de onde o Guerreiro refuta, de modo específico, o pensamento social sobre o negro no Brasil elaborado até sua época e, de modo geral, as ciências sociais como um 
todo (Brito, 2012). Além disso, ela é também a partir de onde Ramos propõe, por um lado, as técnicas de "sociodrama" ou "psicodrama" como exemplos da sociologia do ato aplicada ao pensamento social sobre o negro no Brasil e, por outro lado, as suas últimas teorias sobre a ação administrativa aplicada à ética nas organizações. Suas considerações acerca do livro são as seguintes:

Aliás, nessa ocasião eu já tinha publicado o meu primeiro livro, um livro de poemas: O drama de ser dois. É um livro que não tenho mencionado, um livro embaraçoso, meio desconcertante por causa do tema, que e extremamente piegas, religioso. Mas de certa maneira, se uma pessoa fizer um estudo - não de má fé, mas de boa fé, não precisa nem ser simpático a mim, apenas ser objetivamente, de boa fé-, o livro realmente revela toda a minha história. O drama de ser dois é um livro em que eu confesso o meu desconforto permanente com o mundo secular. Nesse poema eu me descrevia como uma espécie de pessoa entre dois mundos que eu não sabia definir. E ainda hoje acho que esse e um traço fundamental do meu perfil: eu não pertenço a nada. Não pertenço a instituições, não tenho fidelidade a coisas sociais; tudo o que é social, para mim é instrumento. Eu não sou de nada, estou sempre à procura de alguma coisa que não é materializada em instituição, em linha de conduta. Ninguém pode confiar em mim em termos de socialidade, de institucionalidade, porque isso não e para mim, não são funções para mim. O meu negócio é outro. De modo que esse livro e um livro seminal! Não tem importância o mérito intrínseco. Poeticamente, não vale nada. Mas é realmente uma expressão do que eu sempre fui. Em inglês existe uma expressão: in betweenners. Estou sempre in between. Nunca estou incluído em nada. As minhas metas são a única coisa em que estou incluído, não há pessoas que me incluam. (Oliveira, 1995, p. 134)

Como já se afirmou, essa pode ser a chave principal para a compreensão do modo como Ramos se vincula aos debates sobre o pensamento social do negro no Brasil. O prestígio que a sua capacidade intelectual lhe permitia gozar, apesar da pouca idade, também é enfatizado nos resultados de sua atuação no início de sua vida profissional, na Secretaria de Educação. Embora Ramos atribua à sorte os benefícios obtidos (como resultado do projeto de criação da Faculdade 
de Filosofia da Bahia ${ }^{4}$ ), está fortemente sugerido que a sua competência acadêmica era manifesta e, por isso mesmo, pode assumir a cátedra de sociologia antes mesmo de ter entrado no curso de ciências sociais.

Aos 24 anos Ramos recebeu uma bolsa de estudos do governo da Bahia para estudar no Rio de Janeiro. Formou-se em ciências sociais pela Faculdade Nacional de Filosofia do Rio de Janeiro, na então Universidade do Brasil, em 1942, e bacharelou-se um ano depois pela Faculdade de Direito também na cidade do Rio de Janeiro.

É interessante ressaltar o modo como Ramos refere-se ao fato de ter sido aluno de Donald Pierson. Existe nesta referência, tal como mostra a citação abaixo, uma valorização extrema pela teoria sociológica norte-americana e, ao mesmo tempo, um desprezo explícito pelo professor tido como aquele que inaugurou técnicas de survey nos estudos em ciências sociais no Brasil.

Uma coisa interessante é que um homem insignificante teve uma importância muito grande na minha formação cultural. Chama-se Donald Pierson [...] deu umas aulas sobre sociologia americana, com que eu não tinha contato. Meu contato era com Le Play, era com a sociologia francesa $[\ldots]$ mas a influência americana foi muito grande. (Oliveira, 1995, p. 139; 141)

Ramos ressalta que em 1943, após a sua for-

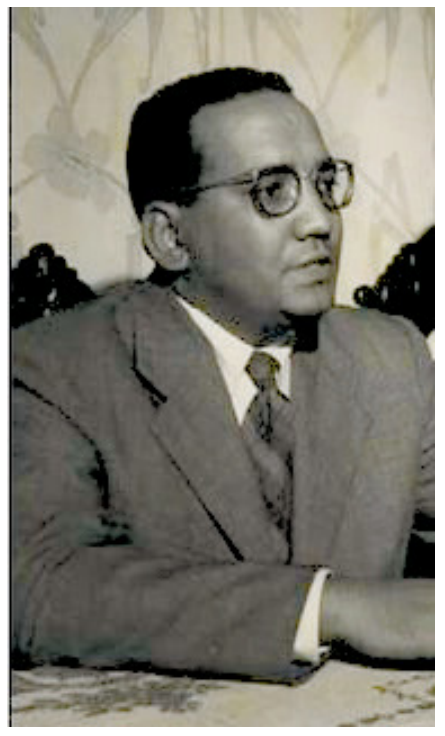
matura, foi indicado para ocupar duas cadeiras na Universidade do Brasil. No entanto, acusado secretamente de "colaboracionista" (em função de seu vínculo com a militância do integralismo quando jovem) não foi nomeado ao cargo. Em seu lugar, assumiu a cadeira de sociologia Luís Costa Pinto e a de ciência política Vítor Nunes Leal. Apesar disso, um ano depois, o integralista San Thiago Dantas, diretor da Faculdade Nacional de Filosofia, o indicou para lecionar um curso no Departamento Nacional da Criança.

É interessante, ainda, considerar o fato de que foi no Departamento Nacional da Criança que Ramos ganhou sua primeira projeção internacional, 
ao publicar a "Sociologia da Mortalidade Infantil"s. Esses estudos, segundo o próprio Ramos, consistiram nas primeiras pesquisas no Brasil que se valeram das técnicas de survey. É possível que este seja um dos elementos que ressaltam sua rejeição à Pierson, visto que este é considerado o iniciador destas técnicas, mas há outras incompatibilidades que também podemos considerar. Por exemplo, a sociologia norte-americana, em especial a Escola de Chicago, influenciou um campo de conhecimento sociológico guiado pela neutralidade e pela objetividade. Mesmo tendo se apropriado explicitamente das técnicas de pesquisa trazidas por esta escola, Guerreiro Ramos se colocou contrário a este tipo de sociologia, o que tornou sua crítica evidente ao propor uma "sociologia em mangas de camisa".

No final do ano de 1943, após viver um ano com a ajuda dos amigos em função da dificuldade para conseguir o primeiro emprego, Ramos foi nomeado técnico de administração do Departamento Administrativo do Serviço Público (DASP). Sua função consistia basicamente em analisar projetos de organização de departamentos, como o Departamento de Agricultura, penitenciária, polícia, e também desempenhou a chefia na seção de recrutamento de pessoal para o governo federal. Apesar do caráter meramente instrumental da função, Guerreiro continuava escrevendo para a "Revista do Serviço Público" e "Cultura Política". Por um lado, tinha se tornado gestor público encarregado da organização burocrática e, por outro lado, se ocupava das análises dos fundamentos sociológicos da organização pública. Estava assim preparado o terreno para a recepção singular da obra weberiana e foi neste contexto que Weber tornou sua grande influência, principalmente pela leitura da "Economia e Sociedade". Assim, declara Ramos que "[...] a influência mais poderosa desde os anos 40 até hoje, em termos da minha profissão de homem da ciência social, é Max Weber." (Oliveira, 1995, p. 144).

Entre 1949 e 1950 Ramos torna-se um dos principais ativistas do TEN. Como coordenador do departamento de estudos e pesquisa do Instituto Nacional do Negro, Ramos promove cursos de alfabetização, colabora com a organização da Conferência Nacional do Negro (1949) e com o Primeiro Congresso do Negro Brasileiro (1950). Foi 


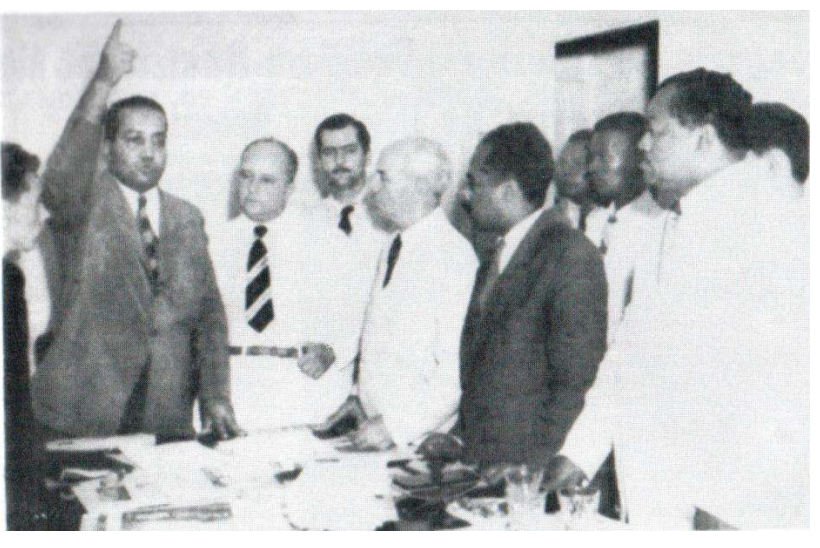

um dos mentores das intervenções artísticas naquela que seria considerada a fase mais importante do TEN: “[...] instalou o Museu do Negro, encenou algumas montagens em teatros do Rio de Janeiro e realizou concursos de beleza, denominados de Rainha das Mulatas e de Boneca de Piche" (Domingues, 2008, p. 263). Segundo a análise de Domingues, o grupo de ativistas do TEN primou por protagonizar ações polêmicas, as quais tinham repercussão na imprensa. "Sua finalidade era chamar a atenção da opinião pública para o problema do negro. Dentro desse espírito, promoveu o concurso de artes plásticas, em 1955, tendo como tema central Cristo Negro." (Domingues, 2008, p. 263).

A partir de 1951, convidado a participar do segundo governo de Getúlio Vargas, Guerreiro passa a trabalhar na Casa Civil como assessor do presidente. Ao lado de Rômulo Almeida, Jesus Soares Pereira e Inácio Rangel, sua função consiste em elaborar projetos, redigir discursos e mensagens presidenciais. Nesse contexto ocorreu tanto o aumento do interesse pela participação no

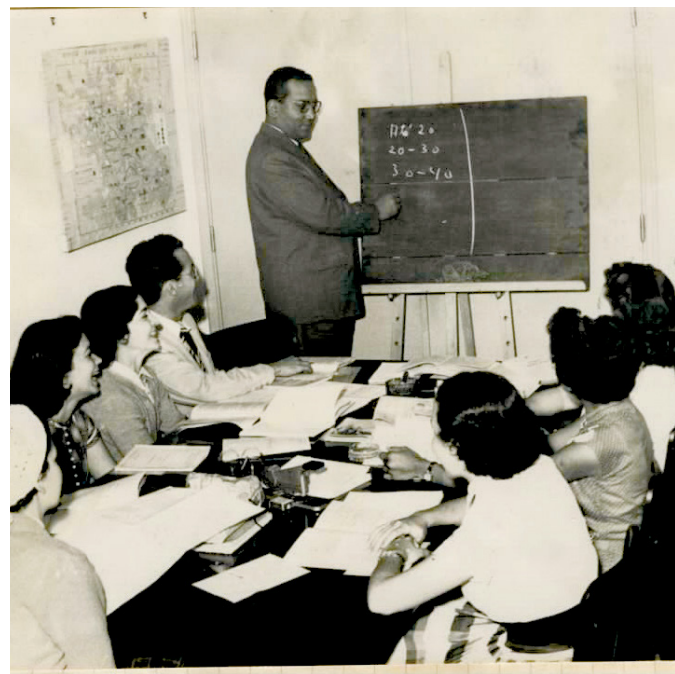
legislativo, na medida em que se aproximou do PTB, como o aumento do interesse pela participação no executivo. Pois, foi nesta época, diz ele, “[...] comecei a compreender o governo do Brasil, comecei a ver o que é a presidência da República. O governo de Getúlio foi muito importante para eu compreender o Brasil." (Oliveira, 1995, p. 147).

Em 1952, Ramos participou tanto da fundação da Escola Brasi- 
leira de Administração Pública (EBAP) - permanecendo vinculado até 1971, como da consolidação do "grupo de Itatiaia"6 (Bariani, 2005, p. 250). Em 1953, em função da consolidação do grupo de estudos sobre os problemas brasileiros, o grupo remanescente das reuniões em Itatiaia cria o Instituto Brasileiro de Economia, Sociologia e Política (IBESP) com Hélio Jaguaribe, Rômulo Almeida, Inácio Rangel, Roland Corbisier. O resultado destas discussões foram editados com o nome de "Cadernos de Nosso Tempo" e publicados entre 1953 e 1956. No total, foram cinco volumes que expressam de modo profundo o fenômeno social da época. Segundo Schwartzman ( 1979 , p. 3), os colaboradores foram Alberto Guerreiro Ramos, Cândido Mendes de Almeida, Carlos Luís Andrade, Ewaldo Correia Lima, Fábio Breves, Heitor Lima Rocha, Helio Jaguaribe, Hermes Lima, Ignácio Rangel, João Paulo de Almeida Magalhães, José Ribeiro de Lira, Jorge Abelardo Ramos, Moacir Félix de Oliveira e Oscar Lorenzo Fernandes.

Se, de fato, o IBESP consistiu no encontro de estudiosos dos problemas nacionais, sua história não se limita a este fato. O IBESP

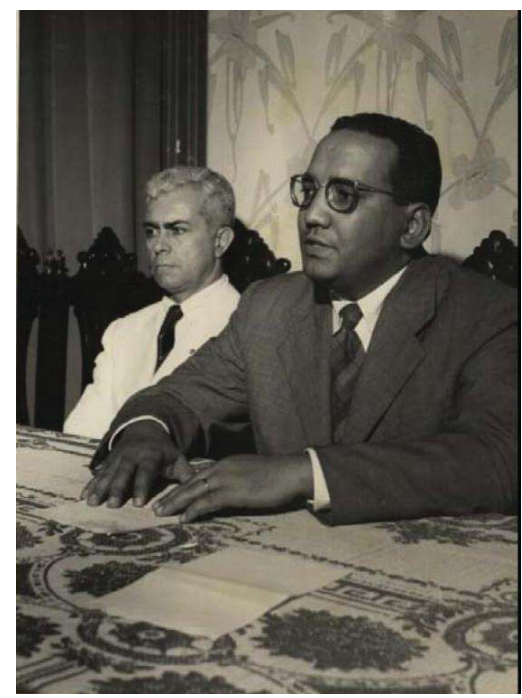
constituiu, também, o núcleo intelectual para a criação do Instituto Superior de Estudos Brasileiros (ISEB ${ }^{7}$ ), em 1955. Segundo Ramos, o ISEB destinava-se ao estudo das ciências sociais, da compreensão crítica da realidade brasileira e da elaboração do referencial teórico que permitisse o desenvolvimento nacional. O ISEB pretendia, assim, ser uma instância de processamento do pensamento brasileiro:

Nós pretendíamos ser uma coisa equivalente - assim era a idéia original - ao Colégio de França. Uma idéia muito, muito alta. O que é o colégio de França? É um órgão que reconhece as pessoas que não têm carreira na universidade francesa, mas que são os grandes luminares, não importa que tenham título ou não. É a grande instituição de consagração. O Colégio de França foi o nosso modelo no ISEB. (Oliveira, 1995, p. 156-157) 
Ramos dirigiu o departamento de sociologia do ISEB até dezembro de 1958, afastando-se por divergência políticas ao discordar do apoio do ISEB à candidatura do Marechal Henrique Lott à presidência da república. As polêmicas e suspeitas levantadas por parte de setores conservadores (como também por intelectuais ligados à Faculdade de Sociologia da USP), acerca do papel institucional e da produção intelectual do ISEB, apontavam e questionavam o apoio recebido desde sua fundação por parte dos governos Kubitschek e Goulart. Por si só, esta teia de relações já seria suficiente para comprometer a idoneidade de Ramos perante o governo militar nos anos de chumbo vindouros. No entanto, outras atividades acadêmicas e intelectuais contribuíram ainda mais para os futuros problemas (Brito, 2012).

Ainda que não estivesse vinculado à ideologia comunista, Ramos não apenas estudou, mas também publicou análises sociológicas nas quais as categorias do pensamento de Marx apareceram como tema central. Esse procedimento encantou os marxistas e, em 1961, foi convidado pelo Partido Comunista para ir à China e, também, à Moscou, com finalidade de realizar um estágio na União Soviética pela Academia Brasileira de Moscou. No entanto, o resultado desta inserção no mundo socialista não seguiu aquilo que era previsto pela cartilha doutrinária da ideologia comunista. As publicações de Ramos acerca do contexto sócio-político russo e chinês não agradaram o Partido Comunista. Pelo contrário, a série de artigos escritos para "O Jornal", em 1962, foi entendida como manifesto de um oportunista e traidor. Como notamos nas seguintes palavras de Ramos, sua posição revelava, por um lado, a falta de fundamento teórico do próprio marxismo, encontrada nos programas de pesquisa desenvolvidos na China e, por outro lado, a limitação das pesquisas russas acerca da realidade social brasileira.

Eu me irritei muito com a China. Passei três meses lá, uma chatice, uma conversa puramente ideológica. Eu ia às bibliotecas e não via nem um Marx; eles só conhecem $\mathrm{O}$ Capital. Um primarismo! E a conversa na União Soviética, uma chatice! Os sujeitos não entendem de Brasil. Aliás, fui muito franco e disse: "Vocês não entendem o Brasil" [...] Escrevi uma série de artigos em que eu dizia que não me via como amigo profissional da União Soviética nem da China, mas era um sujeito que admirava certas 
coisas. Os comunistas ficaram danados comigo: traidor, oportunista etc. (Oliveira, 1995, p. 150-151)

Os anos entre 1961 e 1964 foram decisivos para consolidar sua posição de aliado à política do governo vigente e, também, sua posição oposicionista à política do governo vindouro. Em 1961, Ramos participou da Comissão de Assuntos Econômicos junto à Organização das Nações Unidas (ONU). Além disso, esse foi também o ano de seu ingresso na política partidária, por meio da filiação ao Partido Trabalhista Brasileiro (PTB). No próximo ano, candidatou-se e foi eleito suplente a deputado federal ${ }^{8}$ pelo Estado da Guanabara na legenda formada pelo PTB e pelo Partido Socialista Brasileiro (PSB). Em função da licença concedida ao deputado Leonel Brizola, Ramos assumiu a cadeira entre agosto de 1963 e Abril de 1964, mês em que seus direitos políticos foram cassados pelo Ato Institucional n. 1 .

Exilou-se nos Estados Unidos em 1966 com a finalidade de prosseguir com as atividades intelectuais e acadêmicas que a pátria lhe vedara. Começou a lecionar na Universidade do Sul da Califórnia, e se tornou full professor do programa de doutorado em administração pública. Também lecionou na Yale University e foi professor visitante da Wesleyan University em 1972 e 1973. Regressou ao Brasil depois da anistia, quando lecionou cursos na Universidade Federal de Santa Ca-

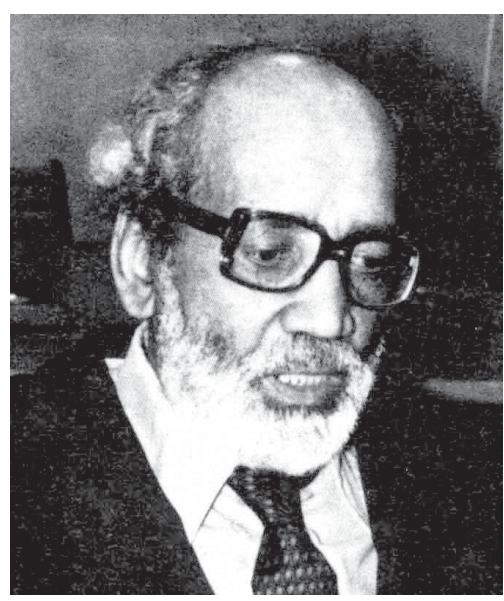
tarina, mas não mais fixou residência no país.

Acerca da data e do local da morte de seu pai, Alberto Guerreiro Ramos Filho (Jusnavegandi, 2016) disse o seguinte:

O velho Guerreiro nos deixou em 6 de abril 1982, no Hospital Cedars-Sinai, em Los Angeles. Recentemente, baralhando seus arquivos pessoais deixados a mim por minha Mãe, eu li que seu óbito oficial no Consulado em Los Angeles o constata como "branco". A vida e estranha, não? Boa sorte com seus estudos, Alberto. (Guerreiro ramos Filho, 2016)

Guerreiro Ramos morreu aos 67 anos, em função de um câncer. 


\section{O Impacto de Guerreiro Ramos na Produção Bibliográfica}

Como vimos Guerreiro Ramos foi um homem de cultura que desde muito novo contribuiu para enriquecimento do debate intelectual de sua época. Inúmeras obras, como veremos na última seção, foram produzidas por ele para diferentes áreas do conhecimento, como as Ciências Sociais, a Administração Pública e a Literatura9. Interessanos, portanto, saber qual a repercussão de seu pensamento em outros autores. Para isso, apresentaremos a partir de agora um levantamento dos trabalhos fundamentados em Guerreiro Ramos e/ou em sua obra.

Como fontes de pesquisa foram selecionadas para este estudo: 1) Portal Scielo.org, que reúne diversos periódicos de todas as áreas do conhecimento e 2) Biblioteca Digital Brasileira de Teses e Dissertações (BDTD) do Instituto Brasileiro de Informação em Ciência e Tecnologia (IBCT) $(2000-2015)^{10}$.

Na primeira base de dados, cujos primeiros trabalhos datam de 1997, encontramos ao todo, 44 produções que serão tratadas neste trabalho, nas áreas: a) Ciências Sociais Aplicadas (38); b) Ciências Humanas (8); c) Ciências Biológicas (1). ${ }^{11}$

Na Biblioteca Digital Brasileira de Teses e Dissertação do IBCT, de 2000 a 2015, foram encontrados 52 trabalhos sendo 35 dissertações e 17 teses nas áreas de: a) Administração (38); b) Ciências Humanas (10); c) Educação (1); d) Saúde Coletiva (1); e) Estudos Estratégicos Internacionais; f) Turismo (1).

\subsection{Apresentação dos Resultados}

Esta seção tem por objetivo identificar se existe concentração em relação aos artigos analisados no que se refere ao ano de publicação, aos autores, às instituições de origem e aos periódicos de publicação. 


\subsection{Artigos Publicados no Portal SciELO}

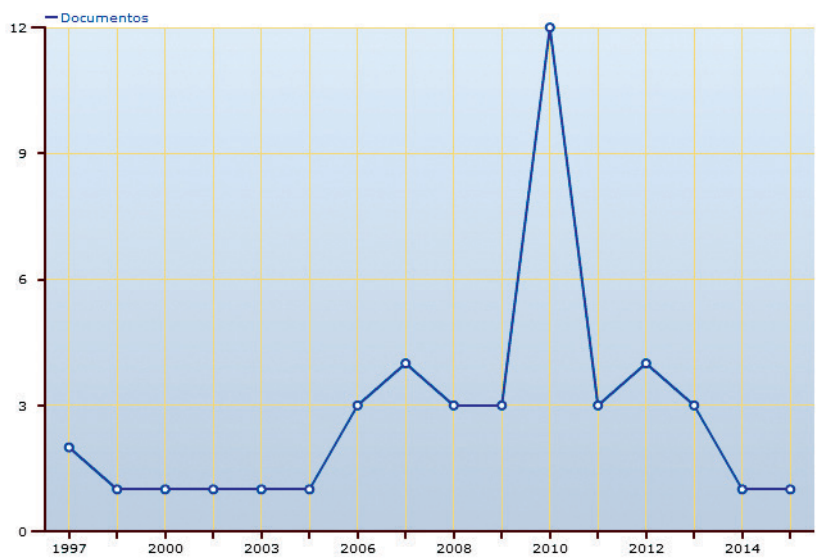

Figura 1: Número de artigos publicados no SciELO por ano Fonte: Portal SciELO (2015)

A Figura 1 mostra uma concentração de trabalhos que tratam do autor Guerreiro Ramos ou de sua obra no ano de 2010. É importante considerar que o método de pesquisa por meio digital, aplicado neste estudo pode ter favorecido o aparecimento deste pico, já que o desenvolvimento tecnológico pode ter permitido maior publicação em periódicos com o passar dos anos, mas a baixa presença de artigos em 2009-2008 e a partir de 2012 reforça a percepção de que em 2010 houve maior destaque para o pensador.

Os autores que escreveram sobre Guerreiro Ramos ou sobre sua teoria são diversos e poucos se repetiram, como Ana Paula Paes de Paula, que aparece em artigos de quatro diferentes revistas, e Sérgio Luís Boeira, Ariston Azevêdo, Marcos Chor Maio, Muryatan Santana Barbosa, Sandro Trescastro e Valdir Fernandes, que aparecem em ao menos dois artigos diferentes, como coautores, ou único autor.

Ao analisar a distribuição dos artigos por periódicos nota-se que a Cadernos EBAPE.BR, patrocinada pela Fundação Getúlio Vargas (FGV), detém a maior parte das publicações, com treze artigo, seguida pela revista Organização ef Sociedade, da UFBA, com onze publicações e com menos artigos, apenas três, está a Revista Administração de Empresas, também da FGV, todas elas como foco na área de Administração. 
Ainda com apenas três publicações está a Revista do Departamento de Sociologia da Universidade de Brasília Sociedade e Estado, seguida por outras duas revistas de Administração a RAM, da Mackenzei e a Revista de Administração Pública, da FGV, com dois artigos cada. As demais revistas publicaram um artigo e têm ênfase em diferentes áreas como Sociologia e Ciências Sociais (Cadernos CRH, Dados, Revista Brasileira de Ciências Sociais, Sociologias e Tempo Social), Administração (BAR, Revista Brasileira e Portuguesa de Administração), Educação (Revista Brasileira de Educação), História (Revista Brasileira de História) e Interdisciplinar (Ambiente e Sociedade), conforme mostra a Figura 2.

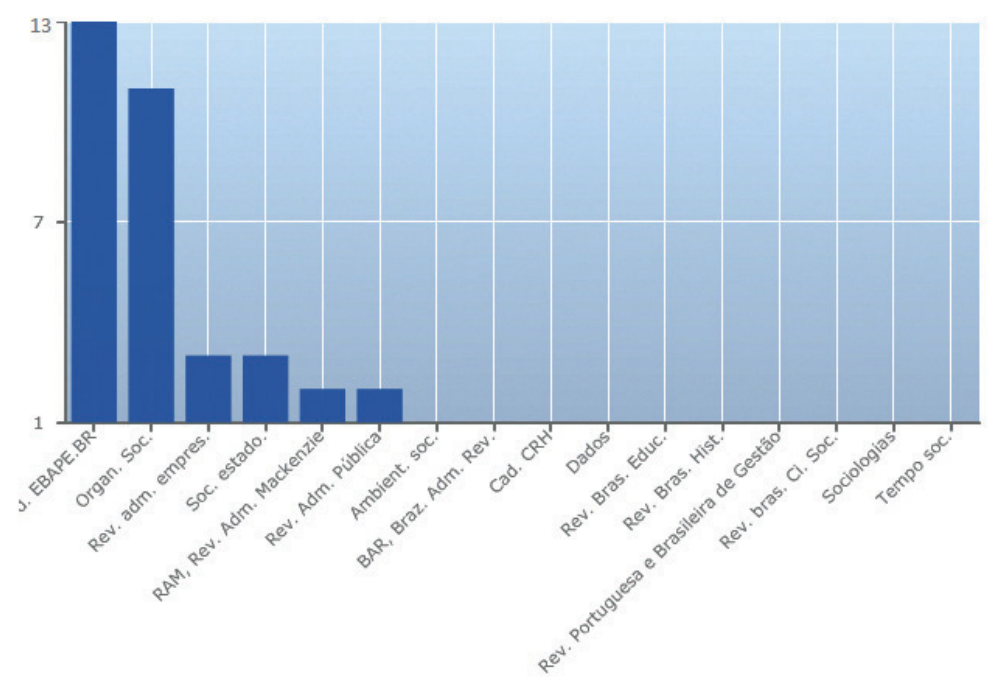

Figura 2: Artigos distribuídos por periódicos

Fonte: Portal SciELO (2015)

\subsection{Teses e Dissertações BDTD-IBCT}

Foram levantados 52 trabalhos, 35 dissertações e 17 teses, de 2000 a $2015^{12}$, conforme mostra a Figura 3. Nota-se novamente que em 2010 houve um aumento dos trabalhos que usam o autor e a obra. 


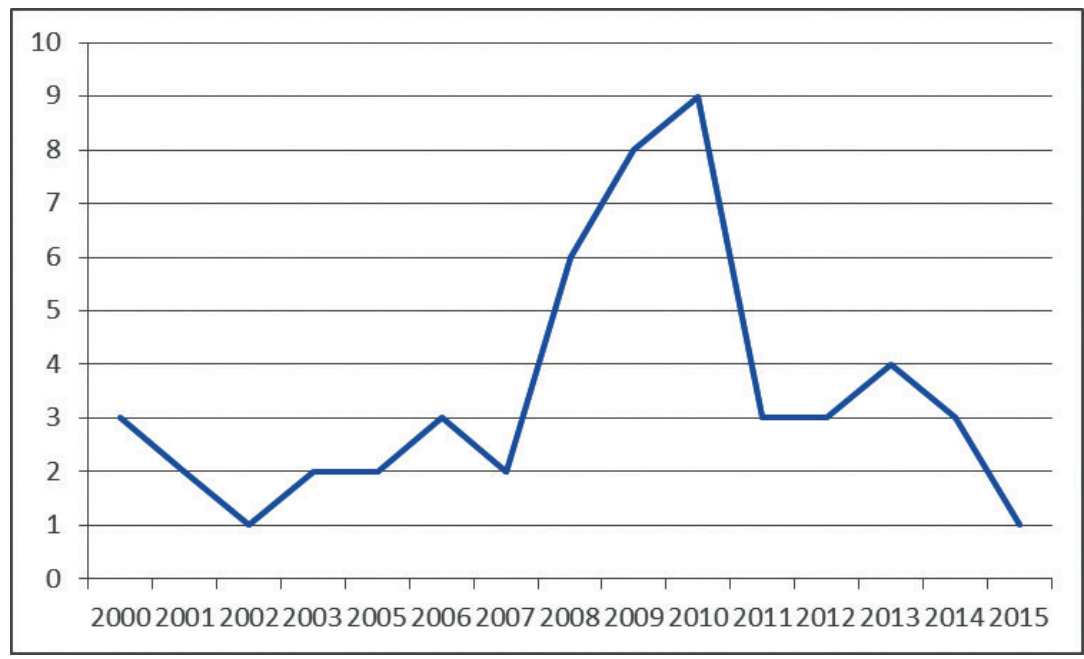

Figura 3: Teses e Dissertações por ano

Fonte: Elaborada pelos autores deste artigo com base em BDTD-IBCT

Os autores não se repetiram em nenhum trabalho publicado no BDTD, porém Sérgio Luís Boeira, Ariston Azevêdo reaparecem com suas teses de doutorado, sendo o primeiro em: "Atrás da cortina de fumaça: tabaco, tabagismo e meio ambiente - estratégias da indústria e dilemas da crítica" (2000) trabalho no qual a teoria de Guerreiro Ramos é usada como contribuição para a análise proposta pela pesquisa, enquanto o segundo em: "A sociologia antropocêntrica de Alberto Guerreiro Ramos" (2006) elaborou um trabalho extenso que percorre os escritos do pensador desde a juventude até a maturidade focando nos aspectos antropológicos e antropocêntricos, constituindo o primeiro estudo por ordem de relevância apresentado pela base de dados.

Na análise da origem dos trabalhos por instituições nota-se que a FGV permanece como maior fonte de trabalhos acadêmicos que utilizam o sociólogo como fundamentação, com dez dissertações e três teses, seguida pela UFGRS com cinco dissertações e duas teses, e pela UFSC com três dissertações e duas teses. Conforme apresenta a Figura 4. 


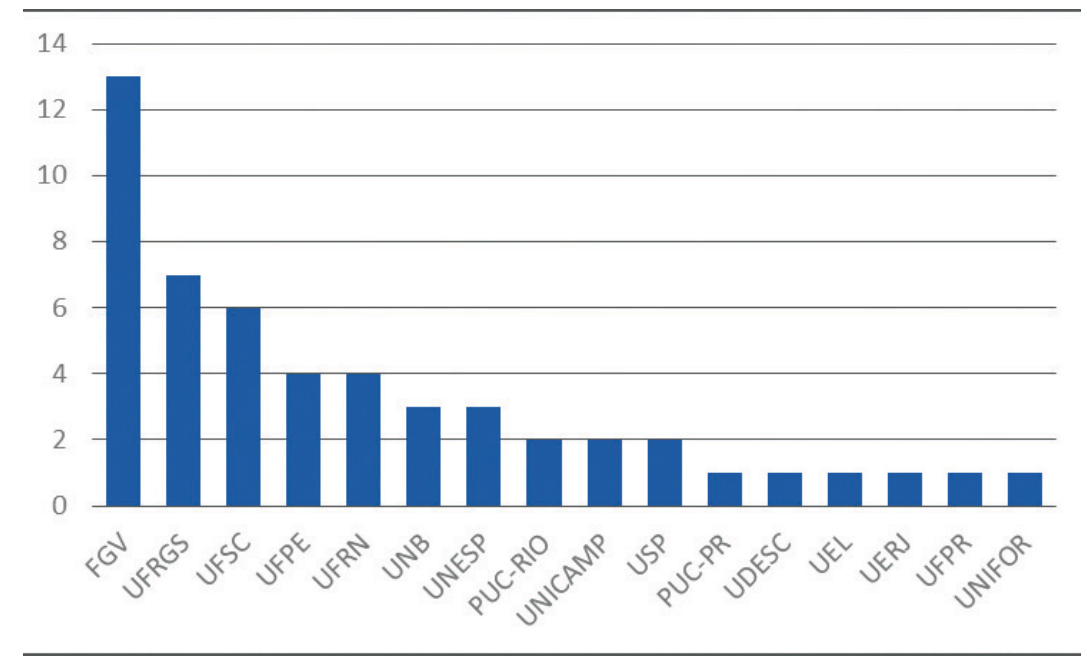

Figura 4: Trabalhos por instituição

Fonte: Elaborada pelos autores deste artigo com base em BDTD-IBCT

Embora Guerreiro Ramos tenha sido um importante sociólogo, o fato de o maior número de publicações serem feitas em revistas de Administração, em especial da FGV, pode estar relacionado com o fato de o pensador ter lecionado na Escola Brasileira de Administração Pública desta instituição e por ter escrito grandes obras nesta área como: "A nova ciência das organizações: uma reconceituação da riqueza das nações" (1989); "Administração e Contexto Brasileiro - Esboço de uma Teoria Geral da Administração" (1983); "Sociologia; Teoria das Organizações - Um Estudo Supra Partidário (1983)"; e "Administração e Estratégia do Desenvolvimento - Elementos de uma Sociologia Especial da Administração" (1966). Porém a pouca atenção dada ao intelectual no campo das ciências humanas ainda carece de maiores explicações.

Alguns autores trouxeram alguns motivos possíveis para a marginalização de Guerreiro Ramos no meio acadêmico brasileiro. Para citar algumas, segundo Maio (2000), esse fato se deu pelo envolvimento do pensador com o movimento integralista. Já Oliveira (1995) justifica que os ataques feitos às figuras de grande prestígio nas ciências sociais brasileiras teria lhe rendido o ostracismo. Por outro lado, Figueiredo e Grosfoguel (2007) argumentam que embora muitas das explicações dadas para o relativo esquecimento de Guerreiro Ramos girem em 
torno de sua personalidade polêmica e contestadora, outra perspectiva possível para se pensar essa questão é a condição de autor negro num meio que era, e continua sendo, hegemonicamente branco.

Contudo, a desatenção dada ao sociólogo e muitas vezes o desconhecimento de sua obra corrobora com a crítica feita pelo próprio Guerreiro Ramos à alienação e eurocentrismo da sociologia brasileira, ou seja, ao desinteresse pela proposta epistemológica exemplificada como uma "sociologia em mangas de camisa".

\section{Levantamento das Obras de Guerreiro}

Nesta parte apresentaremos o levantamento das principais obras escritas por Guerreiro Ramos. Alguns esforços de reunir a vasta produção deste autor já foram realizados. Segundo Azevedo (2006), mais de 250 obras são atribuídas ao autor, além de 71 pronunciamentos feitos na Câmara dos deputados e apenas oito meses (agosto de 1963 a abril de 1964). Nesse ensaio serão considerados apenas os livros que foram escritos pelo autor, em sua primeira edição (quando localizada), em ordem cronológica.

\subsection{Principais Obras}

GUERREIRO RAMOS, A. O drama de ser dois (poesias). Salvador, 1937. GUERREIRO RAMOS, A. Aspectos sociológicos da puericultura. Rio de Janeiro: Imprensa Nacional, 1944.

GUERREIRO RAMOS, A.; GARCIA, Evaldo da Silva. Notícia sobre as pesquisas e os estudos sociológicos no Brasil (1940-1949). Com especial referência a migrações, contatos de raça, colonização e assuntos correlatos. Rio de Janeiro: Conselho de Imigração e Colonização, 1949.

GUERREIRO RAMOS, A.; GARCIA, Evaldo da Silva. Problemas econômicos e sociais do Brasil. Rio de Janeiro: Departamento Nacional da Criança, 1949.

GUERREIRO RAMOS, A. Sociologia do orçamento familiar. Rio de Janeiro: Departamento de Imprensa Nacional, 1950.

GUERREIRO RAMOS, A. Uma introdução ao histórico da organização racional do trabalho (ensaio de sociologia do conhecimento). Rio de Janeiro: Departamento de Imprensa Nacional, 1950. 
GUERREIRO RAMOS, Alberto. O processo da sociologia no Brasil (esquema de uma história de idéias). Rio de Janeiro: Cândido Mendes Júnior, 1953.

GUERREIRO RAMOS, A. Cartilha brasileira do aprendiz de sociólogo: prefácio a uma sociologia nacional. Rio de Janeiro: Cândido Mendes Júnior, 1954.

GUERREIRO RAMOS, A. Curso de história universal da sociologia, pelo professor Alberto Guerreiro Ramos. Rio de Janeiro: Escola Técnica do Comércio, 1954.

GUERREIRO RAMOS, A. Panorama Social do Brasil. Rio de Janeiro: ESG, 1955.

GUERREIRO RAMOS, A. Características psicossociais do povo brasileiro. Rio de Janeiro: ESG, 1955.

GUERREIRO RAMOS, A. Condições sociais do poder nacional. Rio de Janeiro: ISEB, 1957.

GUERREIRO RAMOS, A. Ideologias e segurança nacional. Rio de Janeiro: ISEB, 1957.

GUERREIRO RAMOS, A. Introdução crítica à sociologia brasileira. Rio de Janeiro: Andes, 1957.

GUERREIRO RAMOS, A. La redución sociológica. México: Editora da UAM, 1959.

GUERREIRO RAMOS, A. O problema nacional do Brasil. Rio de Janeiro: Saga, 1960.

GUERREIRO RAMOS, A. A crise de poder no Brasil (problema da revolução nacional brasileira). Rio de Janeiro: Zahar, 1961.

GUERREIRO RAMOS, A. Mito e verdade da revolução brasileira. Rio de Janeiro: Zahar, 1963.

GUERREIRO RAMOS, A. A redução sociológica: introdução ao estudo da razão sociológica. 2. ed. Corrigida e aumentada. Rio de Janeiro: Tempo Brasileiro, 1965.

GUERREIRO RAMOS, A. Administração e estratégia do desenvolvimento: elementos de uma sociologia especial da administração. Rio de Janeiro: FGV, 1966.

GUERREIRO RAMOS, A. O modelo econômico brasileiro: uma apreciação à luz da teoria da delimitação dos sistemas sociais. Florianópolis: Universidade Federal de Santa Catarina/CPGA, 1980. 
GUERREIRO RAMOS, A. Considerações sobre o modelo alocativo do governo brasileiro. Florianópolis: Universidade Federal de Santa Catarina; CPGA, 1980.

GUERREIRO RAMOS, A. Administração e Contexto Brasileiro: esboço de uma Teoria Geral da Administração. Rio de Janeiro: Editora da Fundação Getúlio Vargas, 1983.

GUERREIRO RAMOS, A. A nova ciência das organizações: uma reconceituação da riqueza das nações. Rio de Janeiro: Editora da Fundação Getúlio Vargas, 1989.
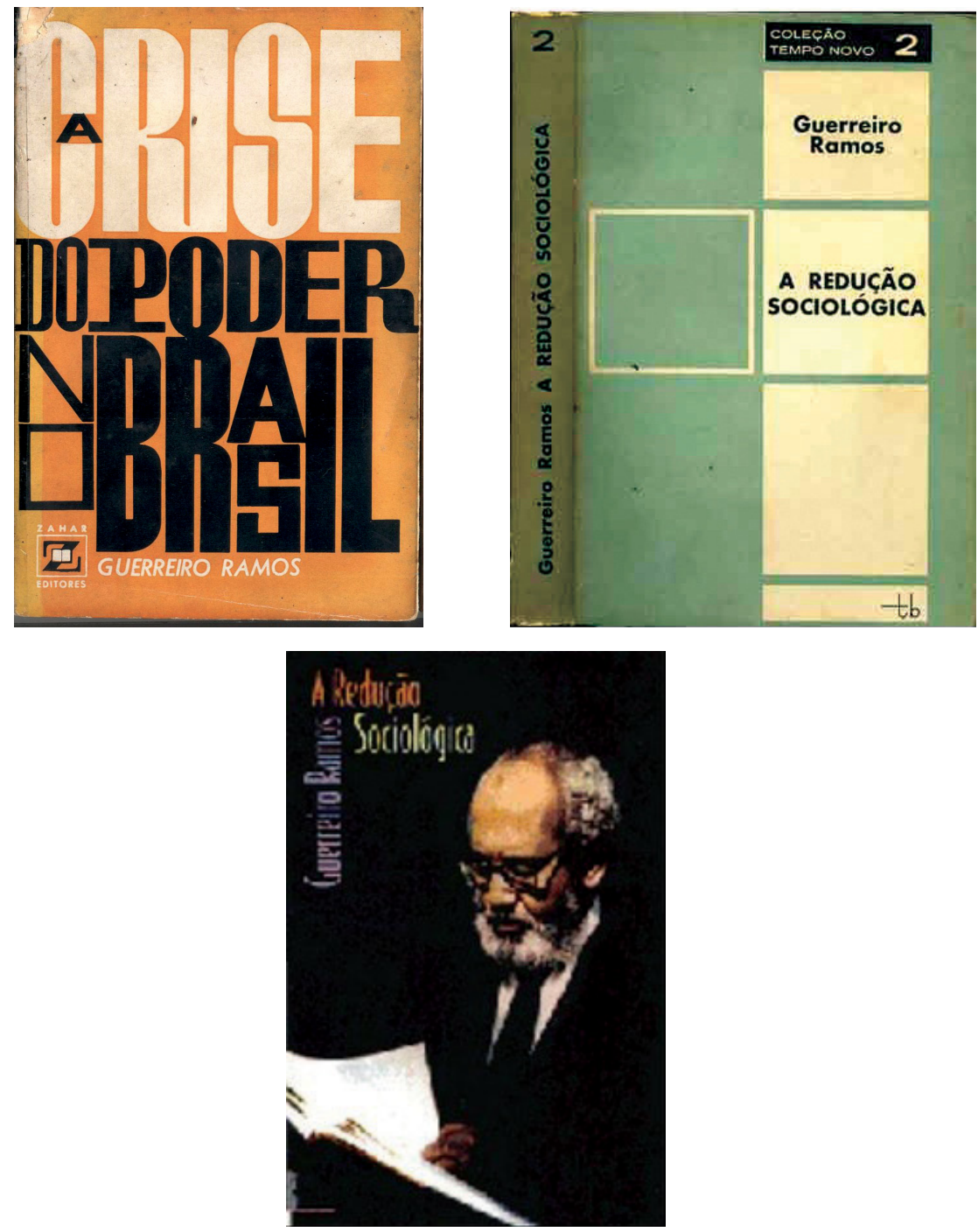


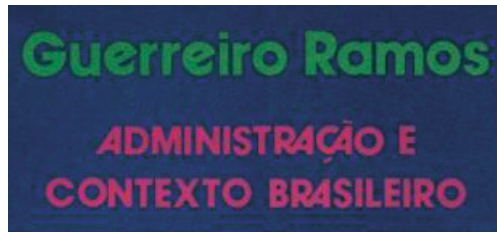

BIBLUOTECA DE ADMINISTRAÇÁO PÚBLICA-12

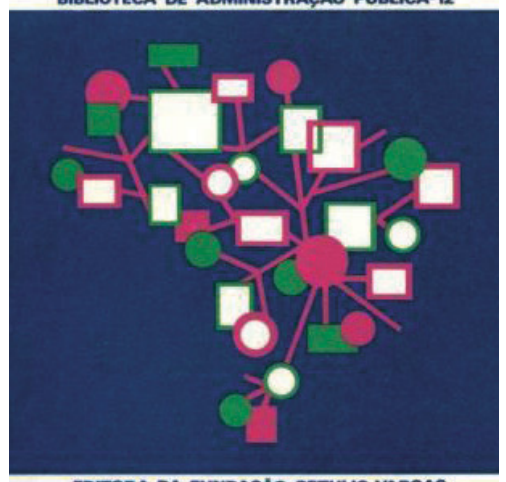

EDITORA DA FUNDAÇAO GETULLO VARGAS
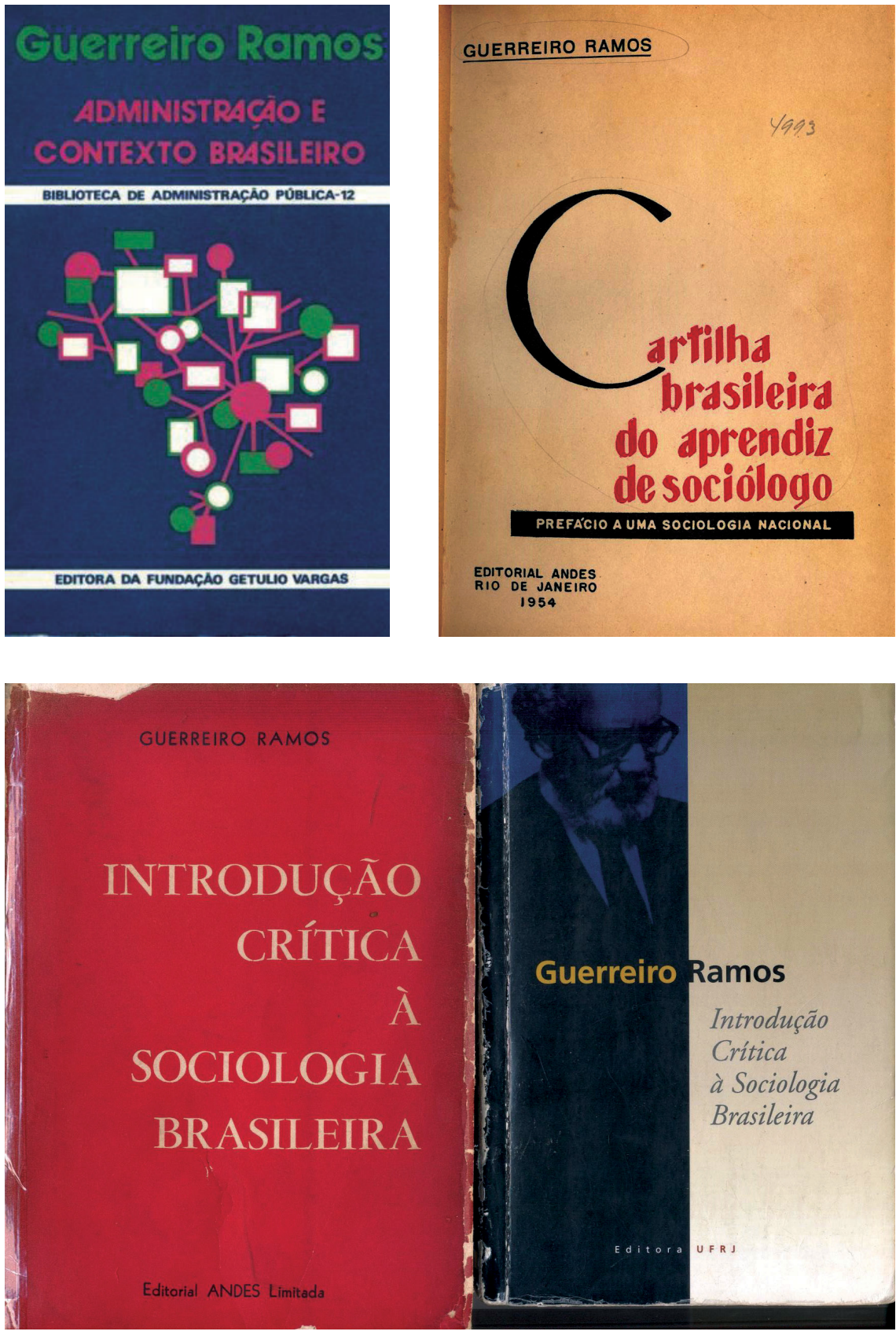

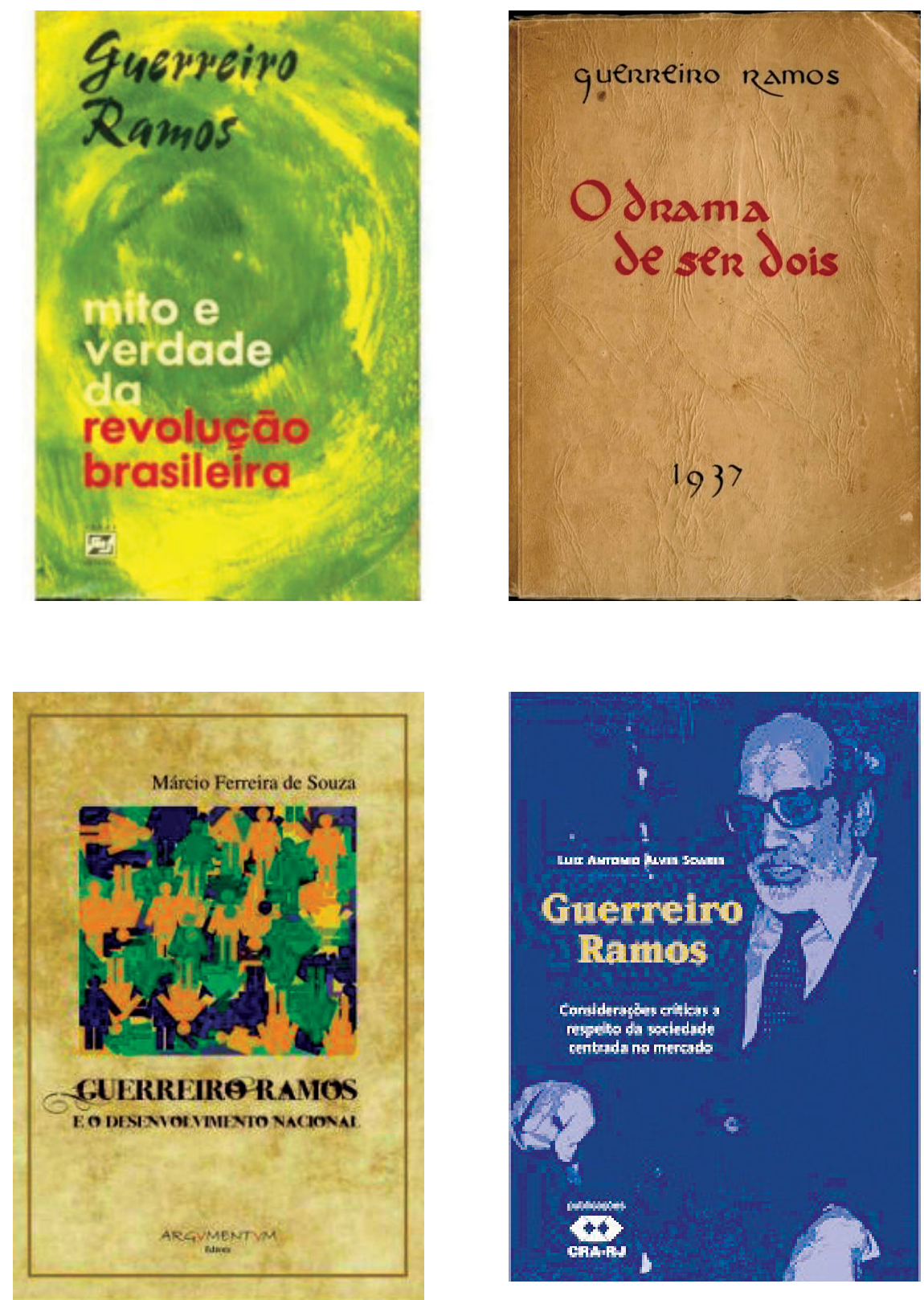


\section{Sociólogo diz que Brasil}

\section{"fabrica" nova revolução}

A possibilidade de uma revanche entre Armadas, "é civil brasileira e as Força social que vivemos, caso o do processo nue a insistir numa politica econômica basicamente.privilegiaoligopólios interna. cionais, os quais dominam amplos setores da economia do Pais".

Esta afirmação foi feita ontem, pelo professor Alberto Guerreiro Ramos. seciólogo na Universidade da Califórnia do Sul (EUA), professor visitante da Universidade de $\mathrm{St}^{*}$ Catarina, membro da delegaça do Brasil, junto à ONU e autor de vários livros e artigos traduzidos no

Guerreiro está no Paraná, executando um trabalho para a Fundação Instituto de Desenvolvimento de Recursos Humanos sobre "A Nova - onde dirigiu o seminário ções", encerrado onter das Organizaencontro foi debater as do livro do professor, temário do seminá. rio. O BRASIL DOMINADO

O sociólogo que participou do planeja mento de alguns governos planejaobserva no atual processo politico nómico que vivemos, "um total deminio do capitalismo externo, o qual domina literalmente o primeiro plano da economia naciona

- Nossa economia, na minha opiniâo é dirigida de fora e o seu segmento principal, que eu chamo de "sistema Oligopolizado de Produção", área de grande sofisticação tecnológica, e que reóne empresas do setor de produçâo de bens de consume ou prestacáo de serviços, e que encontra-se totalmente nas mãos de capitalistas Guecronais.

Guerreiro observa que as empresas de tal grupo (o primeiro entre mais categorias dentro da economia nacional), domiatuam e são essencialmercado em que pois estão essencialmente cosmopolitas, pois estao funcionando articuladas instituicões que operam nos a indústrias instituiçoes que operam nos centros mais - Estas em

zes de cras empresas estrangeiras são cappadrōes de comportamento Brasil. Dominam e deformam consumo no caçao, estilo de vida, hábitos nossa eduaté formas de consciência que por eral, e fabricadas. Na verdade estão "socializando" nosso povo de acordo com os interesses do capitalismo externo.

De acordo com o sociólogo, o Brasil mantém os braços cruzados diante de tal invasão estrangeira, e o Governo federal, através de seu Ministério do Planejamento, privilegia a situação dos oligopólios, em detrimento do empresariado

- A soberania que existe é a do produtor, do dono do oligopólio e não do consumidor, e o pior é que a imprensa bras. cias, principalmente a televisão $e$ as agênmente propaganda, trabalham efetivamente para a manutencão do poder dos A ECONOMIA E OS 5 SISTEMAS

O professor Alberto fica a economia brasjicin con cines mentos básicos: o primeiro é constituido pelo Sistema Oligopolizado de Produção o segundo é formado pelo sistema de.Produçăo de Relativa Competividade; Proceiro é o Sistema Fronteirico, sistema Quase-formal de Microproduc e o quinto, envolvendo os Sistem viais e Comunitários de Producăo

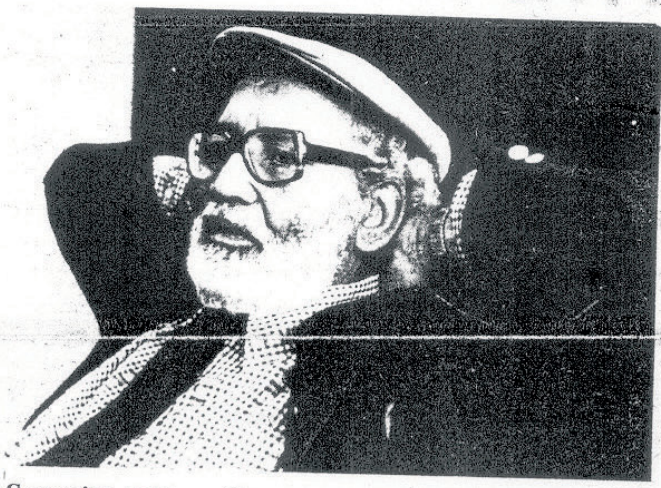

Guerreiro acha o Governo incompetente para gerar

No primeiro atuam empresas que lidan com os principais campos da econom aparelh. elúlidos com a produção de e outros elétricos e eletronicos, remédios gia de produtos da chamada tecnolo gia de ponta, altamente sofisticada e ond lobby e pressón (por mecanismos de apital prisoes No segundo sister

No segundo sistema, operam empresa tro dos modelos clássicos de econo, denmercado. Predominanteme economia de não exclusivamente é representado por empresas médias e pequenas.

No espaco ocupado por essas empresas, a chamada "soberania do consunios" exerce em considerável escala. É um setor mais ocupado pela "burguesia emprese rial brasileira", sujeitas ao "darwinismo economico" - que sujeita as indústrias as leis classicas do mercado, onde somente. como na lei de Darwin, "os mais fortes vencem ou conseguem sobreviver" No sistema Fronteiriço, funcionam empresas em condiçoes altamente criticas. Ou elas adquirem certas caracteristicas que as aproximam dos oligopólios (como co caso de empresas regionais, com dominante participaçáo nos mercados em que atuam), ou, ao contrário, estão sendo alinológicos ou mor força de fatores teccrescens ou mercadológicos a que estão nulizacio prograstas pela internacioeconomia bra-

O Sistema Quase-Formal de Microproducâo reúne os artesōes, profissionais construçảo civil ou reparos serviços de rios de negócios, inclusive biscateirodí. Finalmente na área dos Sistemas viviais e:Comunitários de Produz conacordo com a escala do profesor cáo (de ro), encontramos a associacâo de puerrei nos grupos humanos (entre os guris a pro

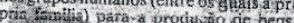
res oens

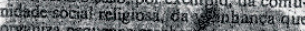
ongtaiza pequenas creclies of prestacio de pequenas fomuhitárloss sooper o

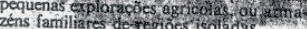

O CONTROegioes isoladas.

Para Guerreiro, no seu estado atual, oconomia brasileira é peca de um sistema cosmopolitano de produçâo e distribuicão margens de dominantes garantem as suas operacões internacios convem em controlam orocessacionais, enquanto a produção no mundo periférico (do capitalismo)

A alternativa para esta situacâo implementação no Brasil de novaça é de sua economía doméstica, fundamh tado numa percepcão mais acurada multiplicidade dos subsistemas de produção que a compóem. Enfim. Brasil deve perseguir em termos econômicos, mentos de numero dois a cinco, conforme o modelo de Guerreiro.

- Está por sefazer no Brasil um novo programa que resulte numa comunhâo de interesses entre setores de nossa tecnoburocracia e setores empresariais estrangeiros e nacionais. Além disso, precisamos de uma chefia executiva mais inteligente. pois no momento temos um Ministério do ressejamento, trabalhando contra os interesses nacionais e cientificamente desin-

\section{BUROCRACIA REPRESSIVA}

O sociólogo flirmou que " acredita que no governo brasileiro, existam pesoas capazes de estarem enxergando que o pais está se transformando em todos os setores de sua sociedade, porém, todos cia repressiva, criada nos tempos de 1964 a qual pensa mais na seguranca nacional do que na segurança do cidadão" - Eu acho que o jargão oficial já está condenado, completamente divorciado da opiniäo pública nacional. As eleicōes de 1982 poderão representar uma cliance para mudar-se o quadro politico nacional maiso rocido social já näo suporta terdo lantas fantisias que vivem prom 3corda para Guerreirc. - O4, o sistema che da sociedade civil man teme, a revansil uma situacũo muito ou ceremos no Braem 1964, com uma mais critica do qu de uma revolta popular em potencial arios, politicos e a nós, vivemos asfixiados por uma burocra Segu s la dade de vida para a povo ressa a ninguém popm as Fisso naã inte nem aos empresários Forcas Armadas 
Belo Horizonte, segunda-feira, 18 de Maio de 1959

¿Aceitei a minha eleição para o Diretorio Nacional do PTB entre outras coisas porque estou conve

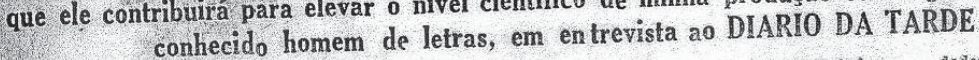

-

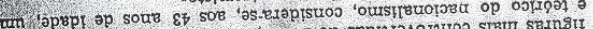

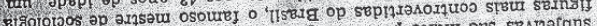
8180iopos ap axpsau osourej sep Eua ofururlatros

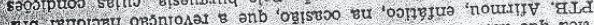

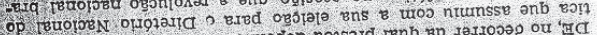

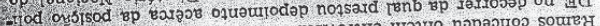

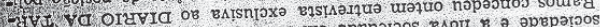

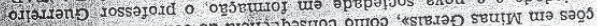

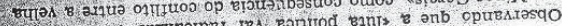

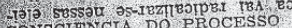

Guetretro Ramos explica ao reporter a uma pergunta as porepectivas de sua patticlpaca pom Hitcica. concretizada agora com sua eleleso para
clonet do PTB:

- $\$ \mathrm{E}^{\circ}$ preciso formar a cons. déncia do processo brasiletro:
Todavia. essa conscténcia năo Todavia essa consciencia por tólas: Nido é algo a que se chegue defirittivamente. A consciencia do nitum processo global de desenvol. vimento como o nosso, muda a cada passo que o pals dá. Portanto a formação da conscienn cla naclonal requer uma atitude

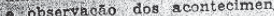
toś Chestiel a conclusåo de que eszotei todas as possibilidades que a cátedra e a funça do magisterio me davam para
a reallidade brasileiras.

para um instante, tira uma baorada do seit charuto, a måo acompanha o ritmo das palaTras: iNesses ultimos anos, atingl o máximo de consciéncla pos. AT:el do processo cadémico de proteosor. Neste momento, tenho a ressor: has condiçóes de um debutante. De alguím que tem que vencer de professor para, sob o impeativo de melhor servir a colet dace, dar-ceitual mais one osa mals eflicaz. Bsta nova equacta que venho de adotar esit the linpondo uma participe. séo mals profunda no jọgo po. Iilico do bafs e no drama dos
interésses económicos. O proces. so brasllelto está dotado de tal elocidade que o clentista social (principalmente as sobterem riC exatidato nas suas formy 6es, nảo podem contental-se hecer os fatos quando esgeormados em r

o tamoso teorico nacionalista olui thas suas consideraçóes: tro Brasil a noticia dos atra: 15o. I. neceessario, por liso, tarTo. lianto: acompanhados: desde

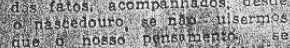

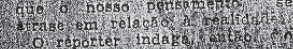

nha eleição para o Diretorio Na. cional do P. T. B. Respondo a essa pergunta da seguinte ma neira: nceitel este posto Dartiane rlo entre outras colsas porcon estou convencido de qu blver tribuirá para elevar o nivel cí entifico de minha produça so. crologica. Na vera este meu nomento que martianrio ja estava vo posto partinha produção academica principalmente nos mous dois ultimos livros: cIn. troducta critica a sociologia brasileiras e $<A$ reducão sociologicay. Nesses dois livros, como em outros trabalhos meno. res, tenho a impressão de que, para falar uma linguagem hegeliana, neguei a ciencia do gabinete no gabinete ou ainda gabinete guel a sociologia de gabinete. fazendo sociologia der concreto a despeito do seram sempre as minhas que tiveram sempres. Mas, agora, me é cogitacoes. Mas, oportunidade oferecida me esquistar ou cristall zar numa posiçáo. de dar um passo adlante e de negar a $\mathbf{s 0}$ clologia de gabinete fora do ga. blnete, isto é, na cática social epensando com as măoss, con. fundido com as asplracóes. os movimentos dos trabalhadores dos estudantess.

$$
\text { METODO }
$$
- $₫ \mathrm{O}$ Brasll nåo tem ainda a sociologia que meroce. Na por falta de homens inteligen tes a capazes, mats por falta de uma equacăo metodica que social siste em tornar a oratica o fundamento da elaboraciologia entifica no camso deiro é rico de rentendr sociologico que só po. de ser descoberto por aqueles are se colncam sistematicamen te a servico de suas motr A ESQUERDA responA percunta cutdacio

O reporter qier sabor se o professor Cuerrelro Ramos se consldera um homem de esauercia Explica ele entăo

- Evidentemento é muito diffcli definir em poucra palavras ums posicara politica. Sou 11 momem hou de esquerda, mas na sou um extremista. Sou um bomen de es querda na medida en que lut panjlee-social do Brasat não per-

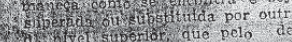

"statu quo" atual da sociedade bra silalra, mas a sua transformação qualitativa". Guerreiro se interroga, entăo: "Quem deve ser o empresario des. sa transformação?"

$\mathrm{E}$, na sequencia, responde-se: - "A este respeito, cheguel a conclusão de que no Brasil o empresario da revolugãa nacional terú de ser o povo. Quando se tra. ta de saber qual seja o ngente principal de revolusa brasileira, a enfase deve ser da. da ao povo, constituldo majorita. riamente detrabalhadores. As condlçóes subjetivas da burguesia brasiletra sao to prolucão na. ra o cometimento da revoluça nacional brasilento polores consil, estabjotivas ideologicas para realizar a revoltccăo naciona ra realzar a burguesia. Cabe. do que a povo liderar o movi ment emancipador nacional bras. leiro. Por incrivel que pareça, no Brasil é o povo que vai pressio nar os quadros dirigentes para acelerar a edificação do capitalis mo brasileiro, porque os benefl ciarlos imediatos do noss o capita llsmo estăo muito distraidos do papel nacional que deve exerces. $O$ poro sabe que, na etapa atual. todas as solucoses das aiveis olnculdades atuais são possivels ain da dentro do regime cap

Colucada em tormos a posiçá politica do profossor. o reporte pede-line uma palavra sobre a po siça de Minas no processo, lem brando palavias anteriores suas em que ele apontava áuns socie
Ales em confitto em Minas. As sinala ele, respondendo: sinaia ele, respondendo: ses dio ficiente tensắ etula socte. de da atin1. lm climax dramatico que $8 \delta$ Jo tus ultrapeusedo de um podo volento Nás na tradicionit batcolpoia minelra a disposiclio para a obtusidade. Desca que vocé se refere está ultrapass do sem rupturas dos quadros democraticoss.

- 40 senhbr acredita que esse conflito deverá se manifestar no proximo pletto?

- A luta eleitoral que val 80 travar certa mu ma opcas elata em titicas logicos, As correntes presenta en linas. mu polos: preservac um dou diranseor da ver qualitativa e progressista das do. Em sima, a luta politica vai do. raficalizar nessas eleicóes om Minas Geraiss.

O ENSINO

A entreviota năo termina an tes que o professor faça uma observaşáo admirativa quanto 80 trabalho que vem sondo reallza-s do na Faculdade de Clencias Econcmicas da UMG. Considera ele que o nivel de ensino daque la escola. no assunto de que 


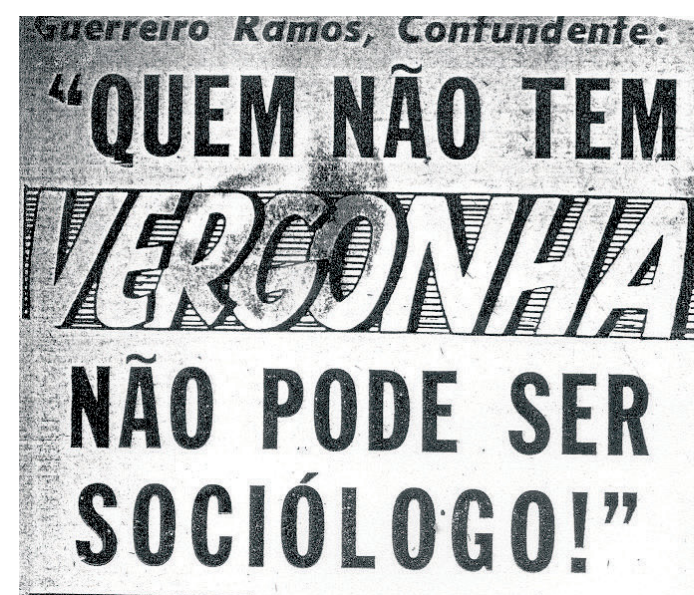

"Gstamas Vivendo no Brasil um Momento Essencialmente Critico" - Está ravendo um Cisma na Sociedade Brasileira, que desaba Dia a Dia - "Vivo Dialéticamente" - Lamento Apenas Que Minha Obra Publicada Não Corres. O PROFESSOR Guerreiro Ramos, pelo relevante prestigio crescente que adquire no Brasil e no plano internacional, pode ser considerado como o nosso sociólogo do de-
senvolvimento, isto é, como o sociólogo em cuja obra se espelham hoie as novas tender cias da sociedade brasileirá. A reportagem de ULTIMA HORA teve opore as novas tendênho a respeito de vários assuntos ligados à sociedade brasileira, no tocante à sta especiaprimeira parte publicumos heporter e professor, surgiu esta palpitante entrevista cui que o leitor podera aferir a profundidade com que trata as questōes sociológicas e a inde-
pendência com que as expóe.

Falando-nos sôbre o moner

atual brasileiro, disse-nos inicial-e a cociedadie em produçāo, em mente o prof. Guerreiro Ramos:

sociolo verio no dominio d

periocos or anichyáo entre

dos críticos da vida de uma so-

gânicos, a sociedade conserue

canalizar os impulsos humanos

dontro de pautas consistentes.

cendutas. A crise surge ruluand

estas paulas năo são mais aptas

a) exercer ump papel organiza-
tójo. deixando por ag vin di-

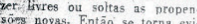

dente unia rutura entre a

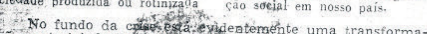

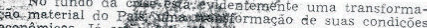

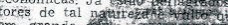

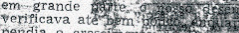

humanos que no Britsit recursos própriamente econômicos e

dem acelerar o nosso progresso material, Estes fatores, rela-

éviamente recentes, estão entretanto, como sugeri acima, e

te me permitem, desvairados, entregues à sua espontaneimortal para or Brasil

Nã́o basta constatar a existên-

cia, entre nós, de fatores auto-

nitil relativamente curto para rea.
tizar a emancipacio do pai

hizar a emancipaçáa do pais -o
que nos obriza a fazer um esfôr-

que nob obriza a fazer um estor-
co pare enquadrar êes novos

Co para encuadrar eses novos
fatôres nos costatutos económicos

criaçấo desses novos estatutos da

sociedade brasileira cxige que se

Widas integradas e que reflitam

sas conscrencia organica de nos-

classe cominantr do Brasil alua

rigente, na medida en que ela

nẳo possui a consciência orgâ.

nica das necessitlades da comu-
midade nacional. Para cer diri-

gemte, falta-lhe uma componen.

e psicologica e ideolúgica -
compreensão da realidade do

paấs como um todo. Esta carên

cia jaeolozica se revela nas mar

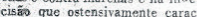
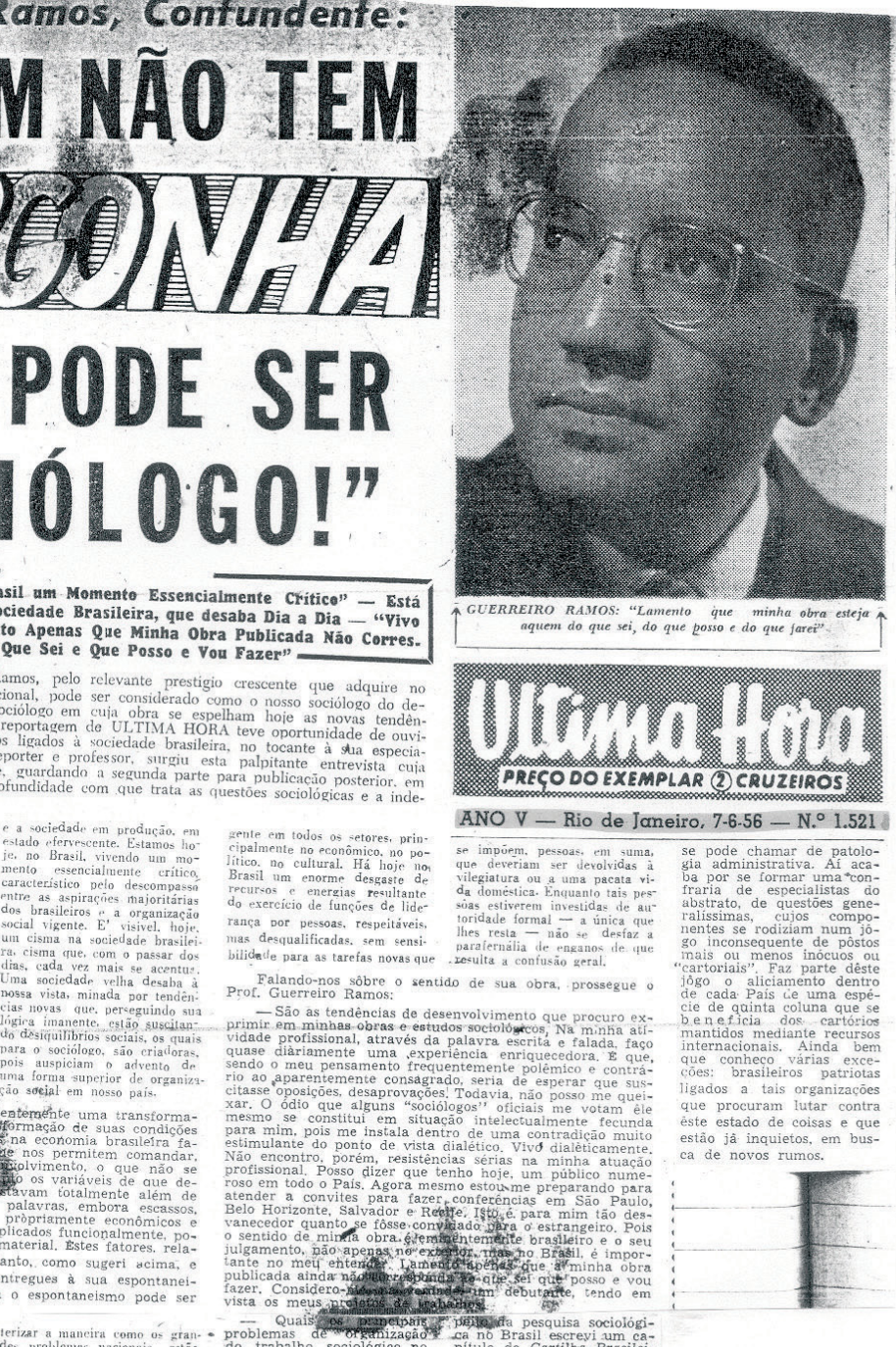

TCUERREIRO RAMOS: "Lamento que minha obra esteja
aquem do que sei, do que posso e do que farei"

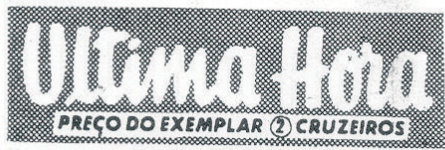

ANO V - Rio de Janeiro, 7-6.56 - N. ${ }^{\circ} 1.521$

se impúem. pessoas, em suma, se pode chamar de patolo-
que deveriam ser devolvidas à gia administrativa. Ai aca-

vilegiatura ou a uma pacata vi-
$d_{a}$ doméstica. Enquanto tais pes-

oridade formal - a unica que

Thes resta - não se desfaz a
paralernatia de enganos de que

bilidacte para as tarefas novas $q$

Falando-nos sôbre o sentido de sua obra, prossegue o
Prof. Guerreiro Ramos:

- São as tendências de desenvolvimento que procuro ex-
primir emm minhas obras e estudos sociologrcos, Na minha ati-

vidade profissional, através da palavra escrita e falada, faço

quase diàriamente uma experiência enriquecedora. E que,
sendo o meu pensamento frequentemente polémico e contrá-
rio do aparentemente consagrado, seria de esperar que sus-

citasse "oposiçōes, desaprovacōess. Todavia, não posso me quei-

que alguns sociol to

para mim, pois me instala dentro de uma contradicão muit

Não encontro, porém, resistências sérias na minha atuação
profissional. Posso dizer que tenho hoje, um público nume-

roso em todo o Pais. Agora mesmo estous me preparando para
atender a convites para fazer, conferéncias em São Paulo,
Belo Horizonte, Salvador

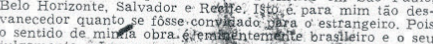

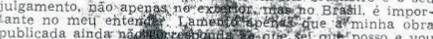

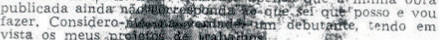

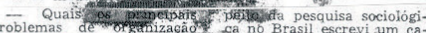

abstrato, de questoes gene-
ralissimas, cujos compo-

nentes se rodiziam num jo-

"mais ou menos inócuos ou

de cada Pais ce uma espécle de quinta coluna que se
beneficia dos cartorio internacionais. Ainda bem coes: brasiteiros patriotas ilgados a tais organizaçōes êste estân ca de novos rumos.

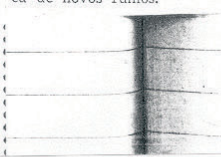

do trabalho sociológico no

pitulo da Cartilha Brasilei

dois. Na minha opinião são

da aplicaçâo dos recursos

no trabalho de pesquisa no

ciais. Várias organizaçôes

ésses recursos. Salvas a

rém de maneira que consi-

dero verdadeiramente pre-
datória. - Estão sendo feitas

pesquías óbvio o que já

sabe sem pesquisa; ou ain-
da, aplicando-se recurso

em investigacōes

de secundarissima impor-

mão de obra qualifica

que poderia ser encaminha-

refas de maior prioridade

ras leviandades, cus-

e cáter pureendmentos

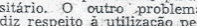

12. Brail dos recursos a que

eito, criundos de or-

or um lado o prestigi

dessas organizacoes parec

medida necessária uma

ude critica em face delas

E assim aceitam-se no Bra-
sil seus projetos simétricos,

ta abstrato, umforme, des

pintando, que nao traduz os

por sere

especificos. Na burocracia

nâo pequena escala o ou oue. 


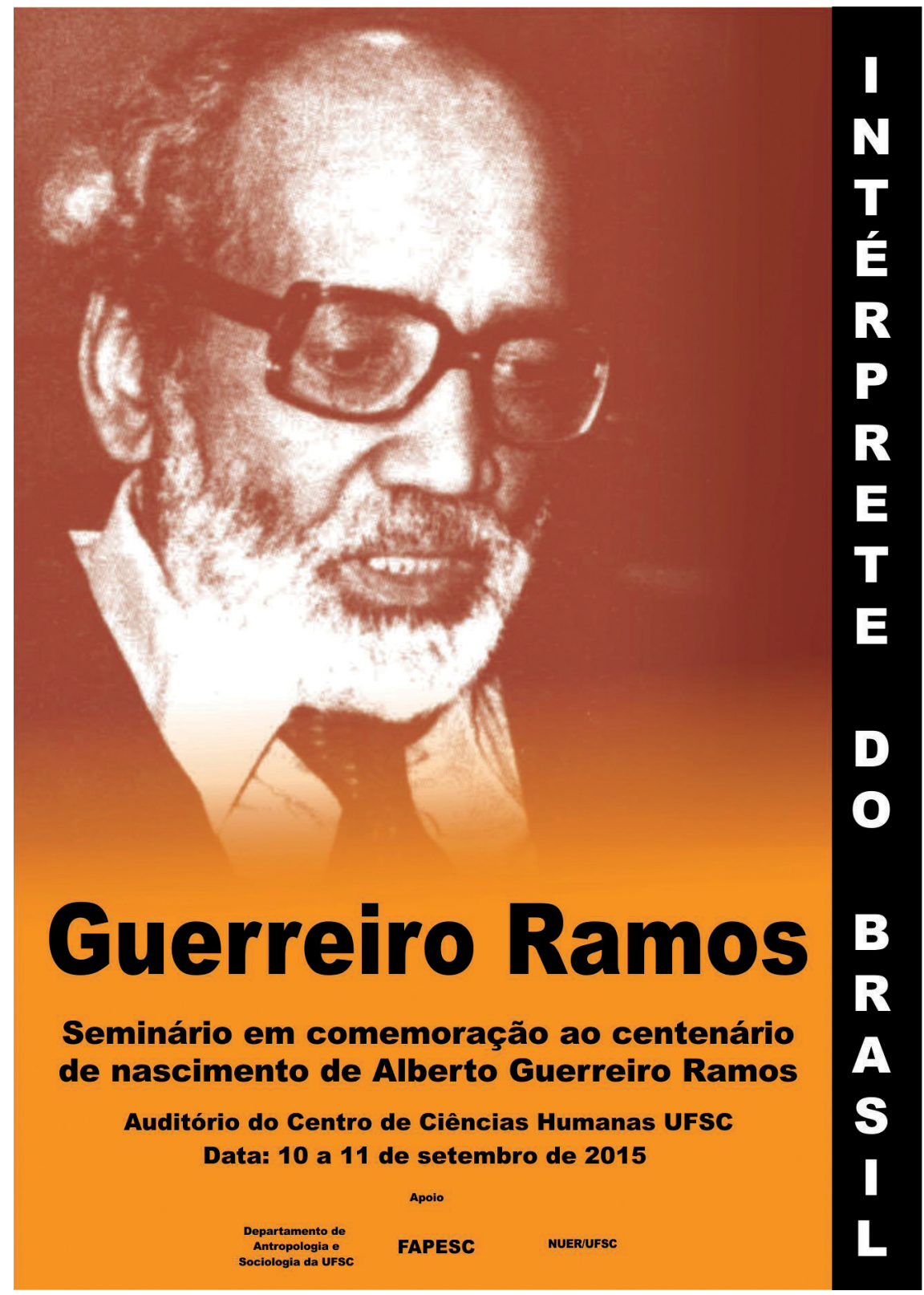




\section{Conclusão}

A partir das apresentações feitas nesta nota biobibliográfica, podemos notar que Guerreiro Ramos foi um intelectual multifacetado, cuja biografia, para ser mais completa, exigiria a elaboração de uma ampla pesquisa em que os resultados fossem tratados num estudo de maior fôlego. Porém, tivemos com intento trazer elementos que ajudem pesquisadores e interessados para conhecer um pouco mais sobre esse autor brasileiro que até hoje é pouco entendido e pouco estudado. Isso pode ser notado pelo baixo impacto de sua obra nos trabalhos pesquisados na sociologia, por exemplo, área para a qual o autor forneceu elementos metodológicos para uma pesquisa que voltasse para a realidade do Brasil, em "A Redução Sociológica" (1965).

Muitas obras de Guerreiro estão hoje perdidas e outras têm exemplares raros em função de não ter havido autorização dos direitos autorais para a reedição das obras. Dessa forma, o levantamento apresentado na terceira sessão deste estudo pode ser uma contribuição inicial para quem desejar aprofundar seus estudos sobre Guerreiro Ramos.

\section{Notas}

Evandro O. Brito é professor adjunto na Universidade Estadual do Centro-Oeste (UNICENTRO), doutor e mestre em filosofia pela Pontifícia Universidade Católica de São Paulo, graduado em Filosofia e Ciências Sociais pela Universidade Federal de Santa Catarina. Como pesquisador, investiga o desenvolvimento da ética nas obras de Franz Brentano e está vinculado aos seguintes grupos de pesquisa: Ética Política e Cidadania (UNICENTRO); Origens da filosofia contemporânea (PUC-SP), Filosofia, arte e educação (UFSC).

** Ilka Boaventura Leite é professora do Departamento e do Programa de Pós-Graduação em Antropologia da Universidade Federal de Santa Catarina, fundadora e coordenadora do NUER (Núcleo de Estudos de Identidades e Relações Interétnicas). Tem formação em História (UFMG, 1980) e Antropologia (USP, 1986). Fez pósdoutorado na Universidade de Chicago (1997) e na Universidade Nova de Lisboa (2007). Seus principais livros são: Antropologia da Viagem; (Ed UFMG, 1996), Negros no Sul do Brasil: invisibilidade e territorialidade (Ed Letras Contemporâneas, 1996 coletânea) e O Legado do Testamento: a Comunidade de Casca em perícia (Ed. UFRGS,2004), Laudos Periciais Antropológicos (ABA/NUER, 2006 coletânea) e Quilombos no Sul do Brasil: perícias antropológicas ( NUER, 2006, coletânea). Suas pesquisas situam-se nas áreas de teoria antropológica, literatura de viagem, relações interétnicas, etnologia afro-brasileira, arte e etnicidade. Tem publicado artigos sobre literatura de viagens, cultura e identidade negra, quilombos, direitos étnicos, políticas de identidade, arte e diáspora africana, perícias antropológicas. 
* Luiza Brandes de Azevedo Ferreira é graduanda do curso de Ciências Sociais da Universidade Federal de Santa Catarina (UFSC) e bolsista da coordenação do projeto rendeiras da Fundação de Estudos e Pesquisas Socioeconômicas.

1 Estas informações, publicadas por seu filho, servem para montar o quebra-cabeças da vida de Guerreiro Ramos definida por ele mesmo como o 'o drama de ser dois': “O Velho Guerreiro me ensinou a sempre lembrar que ele era da Bahia, e tinha um grande orgulho de nossa ancestralidade Africana. O pai de Guerreiro, meu Avo Vitor Juvenal Ramos, nasceu escravo em 1873, mas do tal Ventre Livre. A Mãe dele nasceu na Angola, e foi por sua própria família vendida ao negreiro. Depois de sermos exilados da Pátria Amada, nenhum de nos voltou ao Brasil a não ser para visitar família. [...] Boa sorte sempre". Alberto Guerreiro Ramos Filho. Disponível em: <https://jus.com.br/duvidas/21685/biografia-de-alberto-guerreiro-ramos>. Acesso em: 31 mar. 2016.

2 “G. R. - Além disso, tinha ligações pessoais com Jacques Maritain. Inclusive, ele passou uma vez pela Bahia, e o seu navio encostou no porto. Nós sabíamos, pelo jornal, que o navio traria o grande filósofo Jacques Maritain. Fomos lá e mandamos chamá-lo. Naturalmente, ele não esperava que pudesse ter um contato com intelectuais na Bahia. Ele veio, e nos nós apresentamos como seus leitores. Eu me lembro ate hoje: uma figura angélica, o Maritain, um rosto iluminado. Saímos pela cidade - acho que o navio ficou lá umas nove horas, uma coisa assim -, e ele ficou surpreendido com o conhecimento acurado que nós tínhamos da sua obra. Não conteve a surpresa e nos perguntou: "Mas como é possível isto?". O Afrânio Coutinho e eu éramos as principais pessoas que estavam lá. E nós dissemos que acompanhávamos aquilo, que éramos profundamente influenciados por ele". (Oliveira, 1995, p. 137-138).

3 “G. R. - Eu já escrevia regularmente em O Imparcial. Isso é interessante, escrevi dezenas e dezenas de artigos nesse jornal, era uma espécie de crítico literário. Seguia muito de perto o movimento europeu de idéias. Nessa época, nos anos 30, eu era muito influenciado pela revista francesa L' Esprit, fundada por Emmanuel Mounier, com quem mantive uma certa correspondência. Estava muito a par também de uma outra revista que se chamava L'Ordre Nouveau, dirigida por Amaud Dandier, cujo livro - não me lembro mais do título - foi de grande importância para mim". (Oliveira, 1995, p. 133).

4 “G. R. - Participei da organização da Faculdade de Filosofia de lá, com o irmão do governador Landulfo Alves, Isaías Alves, que era secretário de Educação. E uma das ironias da minha carreira e que, como fundador da Faculdade de Filosofia da Bahia, me tomei catedrático de sociologia sem ter nem mesmo o primeiro ano de ciências sociais.

A. A. - Mas o senhor já tinha o curso de direito?

G.R. - Não tinha nada, não tinha curso nenhum. Como membros da administração Landulfo Alves, fundamos com Isaías Alves a Faculdade de Filosofia. Pela lei, todas as pessoas que fundaram a faculdade tinham o direito de se tornar catedráticos. Então, eu me tornei catedrático de ciência social antes de começar o curso de ciências sociais. E isso que eu chamo de sorte. E a minha vida é cheia de coisas assim". (Oliveira, 1995, p. 132).

5 A produção de Ramos é apresentada supostamente por Abdias, em o Quilombo, nos seguintes termos. "Foi durante seis anos o professor da cadeira 'problemas econômicos e sociais do Brasil' no departamento nacional da criança, ai realizando um trabalho pioneiro em que deu categoria sociológica ao problema da mortalidade 
infantil. Fruto destas investigações de sociologia articuladas com a medicina são 'Aspectos sociológicos de Puericultura' (1944), 'Uma concepção multidimensional do comportamento' (1944), 'Um inquérito sobre quinhentos menores' (1944, em colaboração), 'Problemas econômicos e Sociais do Brasil' (1949) e 'Sociologia da mortalidade Infantil'. (Nascimento, 1950, p. 2; Nascimento, 2003).

6 Como esclarece os estudos de Bariani (2005), “O grupo de Itatiaia teve início a partir de agosto de 1952, no Parque Nacional de Itatiaia (entre RJ e SP), em local cedido pelo Ministério da Agricultura, quando começou a reunir-se - ocasionalmente - um grupo de intelectuais, entre eles paulistas, cariocas, católicos, antigos integralistas, conservadores e outros de posições mais à esquerda. A tônica dos debates, inicialmente, era a discussão teórica por parte de estudiosos que tinham em comum certa configuração intelectual, influências de certos autores e um desejo de impulsionar um pensamento genuinamente brasileiro. Embora o grupo se consolide no Rio de Janeiro (e ali finque raízes), nos primórdios, intelectuais paulistas - sobretudo ligados ao IBF (Instituto Brasileiro de Filosofia) e à Revista Brasileira de Filosofia participaram do começo das discussões em Itatiaia (em 1952). Os paulistas - Roland Corbisier, Ângelo Simões de Arruda, Almeida Salles, Paulo Edmur de Souza Queiroz, José Luiz de Almeida Nogueira Porto e Miguel Reale (também contavam com um professor italiano chamado Luigi Bagolini) - eram liderados por Vicente Ferreira da Silva (filósofo cujos seminários eram muito conhecidos na cidade de São Paulo) que, como outros pensadores, guardava certo distanciamento da institucionalização e do ensino filosófico ministrado na USP - de inspiração européia, francesa em essência, devido às 'missões' - e eram pejorativamente chamados por João Cruz Costa (professor uspiano) de 'filósofos municipais'. Os outros participantes (cariocas), dentre eles os que mais tarde formariam o IBESP e o ISEB e ficariam conhecidos como 'isebianos históricos' (principalmente Guerreiro Ramos, Helio Jaguaribe, Nelson Werneck Sodré e Cândido Mendes de Almeida), tinham com os paulistas - mormente seu líder - algumas influências comuns". (Bariani, 2005, p. 249).

7 Ainda segundo Bariani, "[...] mesmo conhecido como a ante-sala do ISEB, o IBESP não é o passado necessário do ISEB; talvez mesmo o ISEB não seja a realização 'natural' do intento ibespiano. Apesar dos componentes, das influências e das análises que perduraram, o Grupo de Itatiaia e o IBESP têm uma história própria, abordagens diferenciadas e, sobretudo, uma inserção original no contexto brasileiro. Na transição para o ISEB, permaneceram nomes como Helio Jaguaribe, Nelson Werneck Sodré, Roland Corbisier, Ignácio Rangel, Cândido Mendes de Almeida, Guerreiro Ramos etc., e manteve-se a influência da análise econômica da Cepal, da aplicação do existencialismo à realidade social, a posição de engajamento... Todavia, a forma como se organizava e as funções às quais aspirava mudaram. $\mathrm{O}$ ISEB institucionalizou-se, alargou o espectro das análises, agregou novos temas e aventurou-se tanto no debate intelectual quanto social e politicamente, procurando uma maior inserção - seja atuando como interlocutor do Estado e de alguns governos (mormente o de Juscelino Kubitschek), seja ministrando cursos e influenciando intelectuais, estudantes, sindicalistas e representantes da sociedade civil. Como instituição de saber, atuou também como ator político, engajando-se diretamente nas questões e atracando-se na luta ideológica. Já o IBESP procurou congregar intelectuais e constituir-se também como uma intelligentsia, mas acentuando a posição mannheimiana da intersticialidade, da flutuação social dessa camada socialmente 'desvinculada' - embora não ausente das relações de classe (Cf. Mannheim, 1972, 1974) -, funcionando menos como um ator político de posição determinada e mais como ator "ilustrado", de posições caleidoscópicas num amplo leque de análise, 
procurando elaborar sínteses e, concomitantemente, identificar várias facetas da mesma questão e relacionar os interesses das classes aos projetos possíveis. Em suma, o IBESP não se notabilizou como 'partido' político dos intelectuais, e sim como pretensa 'consciência social' teórica dos dilemas do país. Certamente, o ISEB foi uma das formas (possíveis) de desenvolvimento radicalizado do projeto IBESP, talvez uma das mais pragmáticas; daí a derivar seu fracasso é uma outra história".

8 "Em sua atividade parlamentar, Guerreiro apresentou dois projetos de lei: o que dispõe sobre o processamento e averbação de licenças de patentes de invenção no Departamento Nacional da Produção Industrial e o que dispõe sobre o exercício da profissão de técnico de administração. O autor também destaca os principais temas abordados por Guerreiro Ramos: reforma agrária, formação de um mercado interno brasileiro, trabalhismo, profissionalização do serviço público, socialismo, crítica da esquerda, legalização do Partido Comunista". (Malta; Kronemberger, 2009, p. 25).

9 Ver Ariston Azevêdo, 2006.

10 Para a pesquisa foi feito um teste para averiguar se "Alberto Guerreiro Ramos" traria um resultado melhor do que "Guerreiro Ramos", e verificou-se que a segunda opção era mais promissora, pois o autor é referenciado muitas vezes apenas pelos dois sobrenomes. Foram considerados apenas os trabalhos que traziam o nome do pensador no título ou no resumo.

11 Um dos artigos encontrava-se classificado nas três áreas temáticas da SciELO e ou outro em duas, por isso a soma por áreas é maior que a soma de trabalhos

12 Ariston Azêvedo Mendes, em sua tese A sociologia antropocêntrica de Alberto Guerreiro Ramos, apresenta como anexo um levantamento das obras fundamentadas em Guerreiro Ramos, e embora ele não especifique o período considerado nem a metodologia adotada, pode-se notar que os trabalhos datam até os anos 2000, por isso optou-se em pesquisar a partir dessa data para içar o que tem sido feito de novo.

\section{Referências}

\section{AZEVÊDO, A. A Sociologia Antropocêntrica de Alberto Guerreiro}

Ramos. 2006. Tese. Programa de Pós-Graduação em Sociologia Política; UFSC. Florianópolis, 2006.

BARIANI, Edilson. Uma Intelligentisia Nacional: grupo de Itatiaia, IBESP e os Cadernos do Nosso tempo. Caderno CRH, Salvador, v. 18, n. 44, p. 249256, maio-ago. 2005.

\section{BRITO, Evandro O. Dilemas epistemológicos de Guerreiro Ramos.} São José: Editora USJ, 2012.

DOMINGUES, Petrônio. Quilombo (1948-1950): uma polifonia de vozes afro-brasileiras. Ciênc. let., Porto Alegre, n. 44, p. 261-289, jul.-dez. 2008.

FIGUEIREDO, Angela; GROSFOGUEL, Ramón. Por que não Guerreiro Ramos? Novos desafios a serem enfrentados pelas universidades públicas brasileiras. Ciencia e Cultura, São Paulo, v. 59, n. 2, June, 2007. Disponível em: <http://cienciaecultura.bvs.br/scielo.php?script =sci arttext\&pid =S0009-67252007000200016\&lng =en\&nrm=iso $>$. Acesso em: $1^{\circ}$ abr. 2016. 
GUERREIRO RAMOS FILHO, Alberto. Biografia de Alberto Guerreiro Ramos. [2016]. Disponível em: <https://jus.com.br/duvidas/21685/ biografia-de-alberto-guerreiro-ramos > . Acesso em: 31 mar. 2016.

GUERREIRO RAMOS, Alberto. A nova ciência das organizações: uma reconceituação da riqueza das nações. Rio de Janeiro: Editora da Fundação Getúlio Vargas, 1989.

GUERREIRO RAMOS, Alberto. Administração e Contexto Brasileiro: Esboço de uma Teoria Geral da Administração. Rio de Janeiro: Editora da Fundação Getúlio Vargas, 1983.

MAIO, M. C. O projeto Unesco de relações raciais e as trocas intelectuais e políticas Brasil-EUA". Interseções, Rio de Janeiro, Ano 6, n. 1, p. 123-142, 2004.

MAIO, M. C. O Projeto Unesco: ciências sociais e o credo racial brasileiro. Revista da USP, São Paulo, n. 46, p. 115-128, 2000.

MALTA, Marcio; KRONEMBERGER, Thais Soares, Nem melhor nem pior, apenas divergentes: uma contribuição acerca da sociologia brasileira e polêmica entre Florestan Fernandes e Guerreiro Ramos. Achegas.net. Revista de Ciências Políticas, [S.l.], n. 42, agosto-dezembro, 2009. Disponível em: < http://www.achegas.net/numero/42/marcio_thais_42. pdf $>$. Acesso em: 15 jun. 2010.

NASCIMENTO, Abdias. Cartaz: Guerreiro Ramos. Quilombo, n. 9, p. 2, maio. 1950. In: NASCIMENTO, Abdias. Quilombo, Editora 34, 2003.

OLIVEIRA, Lucia Lippi. Entrevista com Guerreiro Ramos: sociologia do Guerreiro. Rio de Janeiro: Editora UERJ, 1995.

OLIVEIRA, Lucia Lippi. A sociologia do guerreiro. Rio de Janeiro: Editora da UFRJ, 1995.

PORTAL SCIELO. Artigos Cadernos EBAPE. [2015]. Disponível em: $<$ http://search.scielo.org/?q= guerreiro+ramos\&lang $=$ pt\&count $=208$ from $=1$ \&output $=$ site $\delta$ sort $=\delta$ format $=$ abstract $\delta f b=\delta$ page $=1>$. Acesso em: 24 nov. 2015.

SCHWARTZMAN, Simon (sel. e introd.). O pensamento nacionalista e os Cadernos de Nosso Tempo. Brasília, DF: UNB/Câmara dos Deputados, 1979. (Biblioteca do pensamento político republicano)

SIQUEIRA, Gabriel. Alberto Guerreiro Ramos. 2008. Disponível em: <http://www.irradiandoluz.com.br/2008/06/alberto-guerreiro-ramos. html >. Acesso em: 31 mar. 2016.

Recebido em 27/02/2016

Aceito em 1\%/03/2016 